\title{
$C_{0} \mathbf{I} \cdot \mathbf{R}^{\circ} \mathbf{P} \cdot \mathrm{E}^{\prime} \mathrm{E}$ \\ Centre Interuniversitaire sur le Risque, les Politiques Économiques et l'Emploi
}

Cahier de recherche/Working Paper 10-46

\section{A Portfolio Approach to Venture Capital Financing}

\author{
Pascal François \\ Georges Hübner
}

Décembre/December 2010

François: Associate professor of Finance, HEC Montréal; Research Fellow, CIRPÉE pascal.francois@hec.ca

Hübner: Deloitte Professor of Financial Management, HEC Management School - University of Liège, Belgium; Associate Professor, School of Economics and Business, Maastricht University, the Netherlands; Founder \& Chief Scientific Officer, Gambit Financial Solutions Ltd, Belgium. Corresponding author: University of Liège, HEC Management School, Rue Louvrex 14 - N1, B-4000 Liège, Belgium. Phone: (+32) 42327428

g.hubner@ulg.ac.be

This paper has benefitted from comments by Eric de Bodt, Georges Dionne, Roland Gillet, Sonia Jimenez-Garces, Sophie Manigart, William Megginson, Auke Plantinga, Armin Schwienbacher, as well as Brandeis University, Skema Business School (Lille) and Paris 1 Panthéon-Sorbonne University seminar participants, the 2010 Benelux Corporate Finance Day (Groningen), the 2010 CIRPÉE Conference, and the 2010 French Finance Association Conference (St-Malo) attendees. We thank Yan Alperovych and Arnaud Cavé for excellent research assistance. Part of this research was completed while the first author was visiting HEC Management School - University of Liège. Pascal François acknowledges financial support from SSHRC. Georges Hübner acknowledges financial support of Deloitte Luxembourg. This research was partly supported by a Belgian Fonds de la Recherche Fondamentale Collective (FRFC) Grant. 


\begin{abstract}
:
This paper studies the contracting choices between an entrepreneur and venture capital investors in a portfolio context. We rely on the mean-variance framework and derive the optimal choices for an entrepreneur with and without the presence of different kinds of venture capitalists. In particular, we show that the entrepreneur always has the incentive to share the risk and benefits of the venture whenever possible. On the basis of their objectives and characteristics, we distinguish the situations of the corporate, independent, and bank-sponsored venture capital funds. Our framework enables us to derive the optimal contract design for the entrepreneur, featuring the choice of investor, the entrepreneur's investment in the venture, and her dilution in the project's equity as a function of her bargaining power. This result allows us to characterize the choice of the investor depending on her cost of equity and debt capital. In addition to project size and risk, entrepreneur's risk aversion turns out to be a critical determinant of VC investor choice -a finding which is strongly supported by a panel analysis of VC fund flows for 5 European countries over the 2002-2009 period.
\end{abstract}

Keywords: Venture capital, Portfolio choice, Entrepreneur, Risk aversion

JEL Classification: G11, G32, G39 


\section{Introduction}

To date, financial research devoted to the determination of the entrepreneur's cost of capital in the context of portfolio choice has preferably applied principles based on the integration of illiquid assets in the CAPM framework (see in particular Meulbroeck, 2001; Kerins et al., 2004). The specificity of the entrepreneurial project, and the impossibility to partition it into transferable financial securities make it difficult to precisely assess the relevant risk premium. Still, within the context of the CAPM, it is possible to move forward to address a mean-variance formulation of the cost of capital. Garvey (2001) introduces an entrepreneur-specific project into the classical framework, and relates the venture's cost of capital to the entrepreneur's risk aversion coefficient. But he further goes in the direction of identifying the cost of capital in a pure portfolio context with only financial assets. So far, the examination of the entrepreneur's problem within the portfolio theory framework has not dealt with the explicit intervention of an outside investor such as a venture capitalist, in spite of the relevance of this scenario.

At another level, the vast majority of the researchers addressing the initial investment relationship between entrepreneurs and venture capitalists focus on information asymmetries, liquidity, costs, and the value-added of the venture. ${ }^{1}$ Upstream from this approach, several issues are still unresolved and can be directly considered within the CAPM equilibrium framework. Amongst the most important ones, the entrepreneur's choice to resort to a venture capitalist raises two questions that directly relate to a portfolio problem: (i) would the availability of a venture capital contract induce the entrepreneur to undertake a profitable venture if she did not otherwise? and (ii) could the characteristics of such a contract enhance the risk-return properties of the entrepreneur's global portfolio? To the best of our knowledge, despite their importance, these questions have not been addressed in the financial literature.

In a dispassionate context where economic agents are rational risk averters with homogeneous

\footnotetext{
${ }^{1}$ See Schwienbacher (2007) for a review.
} 
information, our paper studies the determinants of contracting preferences between the entrepreneur and the investor in a pure portfolio choice context, where allocation decisions are taken on the basis of risk and return characteristics. These preferences feature the choice of the investor type and the characteristics of the contract between the entrepreneur and the selected investor. We deliberately leave aside considerations regarding the positive externalities brought by the investor on the intrinsic value of the venture (i.e. reduction of risk and/or enhancement of expected returns), and concentrate on the pure portfolio issues. Because her financial surface is much larger than the entrepreneur's, the venture capitalist fully perceives the diversification potential of the project in her global portfolio. Hence, the same undertaking induces a lower risk penalty for the professional investor than for the entrepreneur, resulting in an inducement for the entrepreneur to transfer part of project risk and forego a proportionally larger share of project excess return. As a major outcome of this analysis, we get that the entrepreneur always has a rational incentive to seek for an outside investor in the venture, even if she would have undertaken the project anyway and despite the fact that the investor would not bring any added value to the project. Bringing an analogy to insurance policies, the reason for this positive result has to be found by the risk sharing property of the contract, whereby the entrepreneur is better off by giving up some project return in excess of financial asset in exchange of a more-than proportional reduction in her global risk exposure through the venture capital contract.

The second aspect of the venture capital financing decision is related to the choice of which investor type to contract with. The literature devoted to the determinants of this decision is abundant. Besides their usual categorization based on their level of involvement in the venture, potential investors can be discriminated in various ways, such as level of private information (Ueda, 2004; Chemmanur and Chen, 2006), availability of internal resources (Katila et al., 2008; Subramaniam, 2009), experience (Sørensen, 2007), presence of complementarities (Hellmann et al., 2008), perceived experience by entrepreneurs (Bengtsson and Wang, 2010) or project innovativeness (Hirsch and Walz, 2006). Consistent with the context of portfolio theory, we adopt a partitioning of investors with a semantic 
similar to Hirsch and Walz (2006) and Hellmann et al. (2008), based on the distinction between independent, corporate or bank-sponsored venture capital investors. Such a classification enables us to analyze investor characteristics from the point of view of their cost of capital, which would be their major source of difference in a risk-return framework. We derive that the optimal choice of investor depends on her cost of capital components, on the risk aversion level of the entrepreneur and on the characteristics of the project, but is independent of the design of the contract itself. In particular, investor selection is not contingent on the bargaining power of the entrepreneur.

Starting from the same neutral point of view, in the absence of synergy or asymmetric information effects, we endogenize important contractual elements such as the proportion of capital invested and the entrepreneur's equity ownership from the point of view of the relative strength of the contracting agents. Regarding the entrepreneur, our major finding is the separation between the decision of how much to invest in the venture, which only depends on cost, risk level and risk tolerance characteristics, and the arrangement of the share of equity held in the project, after dilution, which depends on the bargaining power of the contractors. Our findings that, whatever the contractual arrangements, the entrepreneur's stake in the project decreases with project risk and increases with her wealth endowment, holds firmly in our framework with symmetric information. We do not have to resort to signaling (Leland and Pyle, 1977) or agency theory (Bitler et al., 2005) to make such a derivation.

The portfolio approach to venture capital has the potential to fill an important gap in the economic motivations of venture investments. We show that, whenever possible, the entrepreneur has always a rational incentive to enter a contract with a venture capitalist. By partitioning venture capital investor groups into corporate, independent, and bank-sponsored funds, we identify the discriminating factors that drive the choices of contractors and contracts in a pure context, i.e. in the absence of externalities induced by the relationship, but where the difference between investors is driven by market imperfections regarding their cost of capital. Our framework enables us to derive the optimal contract design for the entrepreneur, featuring the choice of investor, the entrepreneur's share in 
the venture, and her dilution in the project's equity as a function of her bargaining power. This result allows us to link the optimal investor choice to her cost of equity and debt. Combined with our numerical analysis, the results derived in this study shed new light on the fundamental choices underlying the entrepreneur-investor relationships.

A panel data analysis of venture capital fund flows in five European countries over the 2002-2009 period provides strong support for one of the main predictions of our model, namely the relation between entrepreneur's risk aversion and the choice of venture capital investor type. In line with our predictions, we find a clear tendency to finance with independent funding sources in a low risk aversion environment, while bank-sponsored funds are financed when risk aversion is higher. Furthermore, we theoretically as well as empirically show a substitution effect between bank-sponsored versus corporate funds. We also emphasize the importance of the level of risk aversion on the financing choice for different stages of corporate development.

The paper is structured as follows. Section 2 presents the model setup. In sections 3 and 4, we characterize the preferences and contracts between the entrepreneur and the venture capital investors. The fifth section presents the results of the numerical analysis. In section 6, we report our empirical analysis. Section 7 concludes. Proofs are gathered in the Appendix.

\section{Setup}

Consider a financial market where a set of risky securities and a risk-free asset are traded in the absence of arbitrage. There are two agents: a potential entrepreneur $(e)$ and a financial investor. Both have full access to all traded securities, but may differ in their risk aversion. The entrepreneur, whose endowment is normalized to 1 , has proprietary access to a non-marketed venture investment $\pi$ yielding a rate of return $r_{\pi}$. This venture is not accessible to the investor. We assume that the venture initial outlay is $K>1$ so that the entrepreneur needs additional financing to undertake it. ${ }^{2}$

\footnotetext{
${ }^{2}$ The initial outlay $K$ should be viewed as the amount in the project that cannot be diversified away by combining it with risky assets or by resorting to alternative funding sources, such as family
} 
All portfolio rates of return $\tilde{r}_{j}$ are entirely characterized by their expectation $r_{j} \equiv E\left(\tilde{r}_{j}\right)$, their standard deviation $\sigma_{j} \equiv \sigma\left(\tilde{r}_{j}\right)$ and their beta $\beta_{j m}$ with respect to the market portfolio $m$. The return on the riskless asset is denoted $r_{f}$. For any given portfolio $j$, each agent $a$ assigns a utility score $E\left(U_{a}(j)\right) \equiv U_{j}^{a}=r_{j}-\frac{1}{2} \gamma^{a} \sigma_{j}^{2}$, where $U_{j}^{a}$ is a shortcut for the expected utility operator and $\gamma^{a}$ represents the agent's constant absolute risk aversion coefficient. ${ }^{3}$

The CAPM with two-fund separation holds on the financial market. At equilibrium with financial assets, each investor holds her utility-maximizing portfolio $\phi$ by combining the risk-free asset with the market portfolio with expected return $r_{m}$.

\subsection{Absence of venture capitalist}

When scaled by its relative size, the project's risk-return trade-off $\left(K \sigma_{\pi}, r_{f}+K\left(r_{\pi}-r_{f}\right)\right)$ locates it above the market market CML for the entrepreneur. ${ }^{4}$ In the absence of any financial investor, the entrepreneur has to choose between her initial financial portfolio and the investment in the venture financed through a loan.

The no-venture case If the entrepreneur does not undertake the venture, she holds a portfolio of financial assets whose expected rate of return is:

$$
r_{\phi}^{e}=\frac{\sigma_{\phi}^{e}}{\sigma_{m}} r_{m}+\left(1-\frac{\sigma_{\phi}^{e}}{\sigma_{m}}\right) r_{f}
$$

where

$$
\sigma_{\phi}^{e}=\underset{\sigma}{\arg \max }\left(\frac{\sigma}{\sigma_{m}} r_{m}+\left(1-\frac{\sigma}{\sigma_{m}}\right) r_{f}-\frac{1}{2} \gamma^{e} \sigma^{2}\right)=\frac{r_{m}-r_{f}}{\gamma^{e} \sigma_{m}} .
$$

The entrepreneur's initial utility score is

$$
U_{\phi}^{e}=r_{f}+\frac{1}{2 \gamma^{e}}\left(\frac{r_{m}-r_{f}}{\sigma_{m}}\right)^{2}=r_{f}+\frac{1}{2 \gamma^{e}}\left(\frac{r_{\phi}^{e}-r_{f}}{\sigma_{\phi}^{e}}\right)^{2}
$$

and friends.

${ }^{3}$ Throughout, subscripts and superscripts refer to portfolios and agents, respectively.

${ }^{4}$ Because the project risk is not wholly diversifiable for the investor, the Security Market Line is not adequate for the analysis of the project risk and return. See Garvey (2001) for a discussion. 
The self-financed venture case To self-finance the project, the entrepreneur must borrow $K-1$ at the risk-free rate. ${ }^{5}$ The expected return from her investment in the venture has expectation $r_{f}+K\left(r_{\pi}-r_{f}\right)$ and standard deviation $K \sigma_{\pi}$. The expected utility extracted from the venture project is

$$
U_{\pi}^{e}=r_{f}+K\left(r_{\pi}-r_{f}\right)-\frac{1}{2} \gamma^{e} K^{2} \sigma_{\pi}^{2}
$$

The characterization of the venture is relevant when the following two conditions are met: $(\mathrm{C} 1)$ the investment opportunity induces a higher risk for the entrepreneur than her financial portfolio $\phi$, i.e. $K \sigma_{\pi}>\sigma_{\phi} ;(\mathrm{C} 2)$ the venture investment lies above the CML, i.e. $\frac{r_{\pi}-r_{f}}{\sigma_{\pi}}>\frac{r_{m}-r_{f}}{\sigma_{m}}$.

Proposition 1 Under conditions (C1) and (C2), the venture is self-financed iff

$$
\gamma^{e}<\bar{\gamma}^{e}=\frac{\left(r_{\pi}-r_{f}\right)+\sqrt{\left(r_{\pi}-r_{f}\right)^{2}-\sigma_{\pi}^{2}\left(\frac{r_{m}-r_{f}}{\sigma_{m}}\right)^{2}}}{K \sigma_{\pi}^{2}} .
$$

Given project and market risk-return profiles, the upper bound of entrepreneur's risk aversion for self-financing the venture is inversely related to $K$, which is the project size normalized by the entrepreneur's wealth. That is, all else equal, when the entrepreneur is highly financially constrained (i.e. large $K$ ), it will take a low level of risk aversion for her to accept self-financing. In other words, outside financing from venture capital is more likely to be needed when (i) entrepreneur's risk aversion is high, or (ii) entrepreneur's financial constraint is high. The result of Proposition 1 represents the starting point adopted by Garvey (2001) in his study of the cost of capital for the undiversified investor. Our paper diverges by considering the interaction between the entrepreneur and the investor, while Garvey's analysis focuses on the entrepreneur's portfolio choices and their impact on the required rate of return for the venture.

\footnotetext{
${ }^{5}$ Considering a higher borrowing rate would not change the qualitative insights of the model.
} 


\section{$2.2 \quad$ Availability of venture capital}

The entrepreneur and the investor can enter a venture capital contract. Broadly speaking, such a contract is characterized with two features. First, it specifies the participations of each party. We denote $0 \leq S \leq K$ the amount invested by the entrepreneur, the remainder $(K-S)$ comes from the investor. Second, the contract determines how the expected returns generated by the venture are split between the entrepreneur and the investor. Consistent with our contract characterization, Bengtsson and Ravid (2009) report, in their empirical studies of 1,800 venture capital contracts, six types of contract terms that fundamentally serve two goals: (i) to define the contingent cash flows to be received by the investor (e.g. cumulative dividends or participation clauses) and (ii) to define the contingent cash flows that the investor commits to put on the table (e.g pay-to-play clause). Interestingly, the sharing rule of profits can differ from the initial participations and dilution in venture capital contracts reflect this difference. We therefore denote $d \frac{S}{K}$ the fraction of the expected project revenues that the entrepreneur is entitled to, where $d$ is the dilution factor.

Alternatively, dilution in the venture capital contract can be captured through an interest payment. Taking dilution into account, the entrepreneur obtains an expected $d S r_{\pi}$ from his investment on the venture and $(1-S) r_{f}$ from his remaining endowment. Consider instead a contract where the investor offers the entrepreneur $S r_{\pi}+(1-S) \tau$ as a reward for the total investment, where $\tau$ denotes a riskless contractual transfer rate. The two contracts are made equivalent by setting

$$
\tau=\frac{S}{1-S}(d-1) r_{\pi}+r_{f}
$$

If, for example $S>1$, then the entrepreneur borrows extra money to increase her investment in the venture. The investor offers to lend this amount but proposes to charge a transfer rate $\tau>r_{f}$, hence from equation $(3) d<1$. That is, the entrepreneur agrees to receive a diluted fraction of the project revenues. ${ }^{6}$

\footnotetext{
${ }^{6}$ In actual venture capital contracts, the entrepreneur often issues equity as well as convertible debt and, later, mezzanine financing. It is therefore possible to mix an equity dilution factor $d$ with a
} 
With $d>1$ (i.e. dilution is favorable to the entrepreneur), the entrepreneur enjoys favorable terms for lending $\left(\tau>r_{f}\right.$ if $\left.S<1\right)$ or for borrowing $\left(\tau<r_{f}\right.$ if $\left.S>1\right)$. This situation reflects the reward for the entrepreneur's "sweat equity" in the project. With $d<1$, the reverse is true. Therefore, there is no economic difference between defining a dilution factor $d$ or setting a transfer rate $\tau$. We will further characterize the venture capital contract with the pair $(S, \tau)$.

A contract between the entrepreneur and the investor is feasible if each of them has an incentive to participate. Denote $U^{a}(S, \tau)$ the expected utility extracted by agent $a$ from the contract. A contract is feasible iff

$$
\begin{cases}U^{e}(S, \tau) \geq U_{\phi, \pi}^{e} \equiv \max \left(U_{\phi}^{e}, U_{\pi}^{e}\right) & \text { Entrepreneur's participation constraint } \\ U^{i}(S, \tau) \geq U_{\phi}^{i} & \text { Investor's participation constraint }\end{cases}
$$

A participation constraint becomes binding when the other agent has all the bargaining power in the contract negotiation. If the entrepreneur's participation constraint is binding, the contract is investor-dominant. If the investor's participation constraint is binding, the contract is entrepreneurdominant.

Whichever the investor's type, the entrepreneur's expected utility can be written as

$$
U^{e}(S, \tau)=\tau+S\left(r_{\pi}-\tau\right)-\frac{1}{2} \gamma^{e} S^{2} \sigma_{\pi}^{2}
$$

The investors' commonly shared utility function is discussed below. The investors differ from each other by the parameter value.

\subsection{Investor types}

Building on earlier literature that has recognized some heterogeneity among venture capitalists, we identify three archetypes of investors. First, Hellmann (2002), de Bettignies and Chemla (2003), Chemmanur and Chen (2006), or Goldfarb et al. (2009) make a distinction between independent

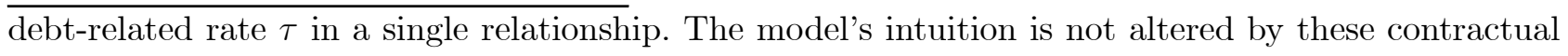
arrangements. 
investors (e.g. business angels) and captive venture capitalists. This distinction is not only organizational or agency-based, but is also related to the goals for the investors who finance the fund. As our setup does not introduce asymmetric information issues, only the second dimension is relevant in our setup. Independent investors' sole objective is to maximize profit through active management of their portfolio of ventures. They have a significant commitment to the VC activity, ${ }^{7}$ and consequently the complement portfolio to each individual venture investment is itself dominated by a number - that can be large - of other ventures. This induces that the risk-return trade-off of the independent's pool of assets cannot be proxied by a financial portfolio such as a market index.

Besides their holding in the venture, shareholders of captive VCs hold a well-diversified portfolio of financial assets. They also have access to financial markets for their leverage decision. Their involvement in the venture capital industry is primarily motivated by the search for additional diversification benefits through investment vehicles showing an attractive return potential at the expense of large specific risks. Because each venture capital investment represents a tiny proportion of a large, balanced portfolio, the specific risks are considered to be diversified away. This interpretation is in line with the common explanation of the large capital inflows from U.S. pension funds in venture capital funds following the 1979 amendment to Employee Retirement Income Security Act's (ERISA's) prudent man rule (Gompers and Lerner, 1998). Manigart et al. (2002) test and confirm the hypothesis that, on average, captive $\mathrm{VC}$ funds require a rate of return from their investments that is lower than the one required by independent venture capitalists. This finding lends support to the diversification argument as a motive for setting up captive VC vehicles.

Another important distinction is made among captive venture capitalists (see e.g. Ueda, 2004, Hirsch and Walz, 2006, Bottazzi et al., 2008, Hellmann et al., 2008, Bengtsson and Wang, 2010): corporate VCs are owned by a parent company whereas bank-dependent VCs are subsidiaries of a banking institution. ${ }^{8}$

\footnotetext{
${ }^{7}$ Bottazzi et al. (2008) document that independent VCs generally display more investor activism than captive VCs.

${ }^{8} \mathrm{~A}$ venture capital fund can also be public, i.e. sponsored by the government. This case is specific
} 
The bank-dependent VC, besides its activity as a venture capitalist, is a financial intermediary and so has a significant deposit and lending activity, which leaves her with better funding and investment conditions than the rest of the market. In our setup, this funding advantage is the major difference with the angel investor and the corporate VC. Such a view is consistent with empirical evidence shown by Hellmann et al. (2008) that a strategic motive for banks to invest in venture capital is to create opportunities for enhanced lending possibilities, which is close to their actual core business as financial intermediaries. Such a view also entails that the key dimension for classifying an investor as banksponsored is the transformation of maturities at large. Therefore, unlike traditional classifications, we associate the sponsoring activities of insurance companies (for their life insurance activities) and pension funds to the ones of financial intermediaries.

Table 1 summarizes the characteristics of each fund provider.

\section{Insert Table 1 here}

To get a better picture of the market, the market shares in total venture capital funds in Europe and in the U.S. according to different investor types are reported in Table 2. As underlined by Mayer et al. (2005), the broad evidence reported in table 2 masks large cross-sectional geographical differences. They report larger proportions of bank VC in Germany, of corporate VC in Israel, of pension funds (assimilated to bank VC in our analysis as they act as a maturity transformation vehicle) in the United Kingdom, and of government VC in the U.K. as well. Evidence from the U.S. shows a greater commitment from endowments and foundations (more than $20 \%$ of the $\mathrm{VC}$ funding) and the virtual absence of government-sponsored venture capital (NVCA, 2004).

\section{Insert Table 2 here}

We use superscripts ind, crp and bnk for the Independent, Corporate or Bank-sponsored types of investors, respectively, for further analysis.

in that the public investor motives go beyond profit maximization. Its analysis requires further assumptions related to social welfare criteria, and is left for future research. 


\section{Characterization of preferences}

Unlike the entrepreneur for whom the project scale represents a substantial fraction of her endowment, the professional investor considers the project as a building block in her financial portfolio. For any profit-maximizing investor with a well-diversified portfolio, the purpose of the investment is to provide the fund's shareholders the highest possible surplus over invested capital. The rationale underlying this reasoning is the fact that, from Tobin's separation theorem, financial investors dissociate their risky investment decision from their financial leverage. Only the latter decision depends on their level of risk tolerance. The only aim of the risky vehicles they invest in is to provide the highest possible residual income, i.e. the surplus over the opportunity costs of their funds. Consequently, the profit-making VC fund's utility function can be written as the expected cash flow less the dollar-cost of capital of the venture, i.e.

$$
U^{i}(S, \tau)=C F^{i}=(K-S)\left(r_{\pi}-\mu^{i}\right)-(1-S)\left(\tau-\kappa^{i}\right), i=i n d, c r p, b n k,
$$

where $\mu^{i}$ and $\kappa^{i}$ represent the opportunity cost of equity and the opportunity cost of risk-free financing/investment, respectively, which can differ from one investor to another. The first term is the VC's net expected profit from the venture, while the second term accounts for the transfer to the entrepreneur. As this utility function is expressed in terms of net cash flow, the corresponding reservation utility $U_{\phi}^{i}$ is set to zero for all $i$.

Next, we turn to the identification of the opportunity costs applicable to each investor.

- The independent venture capital fund, with superscript ind, is held by a number of committed private investors. They view the fund as an actively-managed overlay to their current portfolio, whose aim is to provide a superior Sharpe ratio to a portfolio of traded assets. Hence they assess the project in light of its contribution to the whole risk and return profile of the fund. The cost

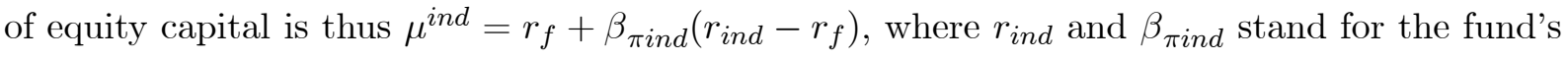
expected return and the project beta with respect to the fund, respectively. 
- The corporate venture capital fund, with superscript $c r p$, represents a large pool of shareholders who are well-diversified. Therefore, in line with Kerins et al. (2004), any investment opportunity is assessed according to its position relative to the security market line. The corporate venture capitalist has otherwise the possibility to borrow or lend on financial markets at the riskless rate.

- The bank-sponsored venture capital fund, with superscript bnk, is a subsidiary of a regulated financial institution. The bank-sponsored venture capitalist starts with no initial endowment but gets funding from its parent institution. It can count on the contractual amount $1-S$ transferred from the entrepreneur via a deposit account at the parent bank (if $S<1$ ) or via a loan contracted at the bank (if $S>1$ ). Being a financial intermediary, the bank can finance loans and invest deposits at better conditions than the market risk-free rate $r_{f} .{ }^{9}$ We denote

$$
r_{b f}= \begin{cases}r_{b l}>r_{f} & \text { if } S>1 \text { (loan) } \\ r_{b d}<r_{f} & \text { if } S<1 \text { (deposit) }\end{cases}
$$

In line with their status, we assume that both the parent and the subsidiary are subject to regulatory capital constraints. Namely, to participate in the venture, the fund has to withdraw the full investment from the parent's equity. As the parent institution is itself fully diversified, we get the cost of equity capital according to the CAPM as for the corporate venture fund. ${ }^{10}$

Table 3 summarizes the inputs for the various investors' utility maximization programs.

\section{Insert Table 3 here}

We now characterize and contrast the sets of contracts between the entrepreneur and the different categories of investors.

\footnotetext{
${ }^{9}$ This rate applies regardless of whether the bank-sponsored VC offers the investor to lend or borrow by the parent's office or whether it negotiates a dilution factor $d$ that will be financed through deposits or invested in loans anyway.

${ }^{10}$ Alternatively, we could refer to Pillar I of the Basle III Accord to obtain that the regulatory capital that the bank has to set aside equals $100 \%$ of the equity investment in the fund.
} 


\section{Characterization of contracts}

\subsection{Feasible contracts}

There exists a continuum of possible contracts $(S, \tau)$ between the entrepreneur and each type of investor, depending on their relative bargaining powers. We will examine the extreme conditions, when either the investor or the entrepreneur can impose the terms of the contract, to assess the scope of feasible contracts.

The entrepreneur-dominant contract with investor $i$, is denoted $\left(S^{[e, i]}, \tau^{[e, i]}\right)$. It corresponds to the pair $(S, \tau)$ that maximizes the entrepreneur's utility while satisfying the investor's participation constraint. Oppositely, the corresponding investor-dominant contract $\left(S^{[i, e]}, \tau^{[i, e]}\right)$ maximizes the investor's utility while binding the entrepreneur's participation constraint.

The following proposition ${ }^{11}$ summarizes the characteristics of the non-degenerate contracts $(S \neq 1)$ :

Proposition 2 If $\mu^{i}-\kappa^{i} \neq \gamma^{e} \sigma_{\pi}^{2}$, a non-degenerate contract $\left(S^{* i}, \tau^{* i}\right)$ between the entrepreneur and the investor $i$ is feasible when the following condition is respected:

$$
\tau^{[e, i]}>\tau^{* i}>\tau^{[i, e]} \text { if } S^{* i}<1 \text { and } \tau^{[e, i]}<\tau^{* i}<\tau^{[i, e]} \text { if } S^{* i}>1
$$

where

$$
\begin{aligned}
\tau^{[e, i]} & \equiv \kappa^{i}+\frac{K-S^{* i}}{1-S^{* i}}\left(r_{\pi}-\mu^{i}\right) \\
\tau^{[i, e]} & \equiv \frac{U_{\phi, \pi}^{e}-S^{* i} r_{\pi}+\frac{1}{2} \gamma^{e}\left(S^{* i}\right)^{2} \sigma_{\pi}^{2}}{1-S^{* i}},
\end{aligned}
$$

and where the entrepreneur's optimal level of investment $S^{* i}$ is the same for any contract and is given by

$$
S^{* i}=S^{[e, i]}=S^{[i, e]}=\min \left(\frac{\mu^{i}-\kappa^{i}}{\gamma^{e} \sigma_{\pi}^{2}}, K\right)
$$

with, for the bank-sponsored $V C$, the additional condition that:

$$
\gamma^{e} \sigma_{\pi}^{2}+r_{b l}<r_{f}+\beta_{\pi m}\left(r_{m}-r_{f}\right) \text { or } \gamma^{e} \sigma_{\pi}^{2}+r_{b d}>r_{f}+\beta_{\pi m}\left(r_{m}-r_{f}\right) .
$$

\footnotetext{
${ }^{11}$ All proofs are gathered in the appendix.
} 
Proposition 2 yields a Corollary with a strong economic relevance.

Corollary 3 If the entrepreneur self-finances the venture, then any venture capital contract is feasible in that it leaves both parties better-off.

Before contracting, the entrepreneur has proprietary access to a project with risk-return profile $\left(\sigma_{\pi}, r_{\pi}\right)$. In one extreme case where the entrepreneur has all the bargaining power (entrepreneurdominant case), she and the venture capitalist will agree on the rate of transfer $\tau^{[e, i]}$, which allows her to shift her utility score from $U_{\phi}^{e}$ to $U_{\max }^{e}$. In the other extreme case where the venture capitalist has all the bargaining power (investor-dominant case), they will agree on the rate of transfer $\tau^{[i, e]}$, which leaves the entrepreneur to the same initial utility score $U_{\phi}^{e}$ (since the investor captures all the benefits of the contract). In all cases, both parties agree on the same entrepreneur's level of investment $S^{*}$.

The optimal share of the entrepreneur is constant regardless of the contract. This share only differs with the identity of the investor. Two extreme cases require some discussion: the corner solution $S=K$ and the no-transfer solution $S=1$.

In the first situation, the entrepreneur takes over the whole project, and borrows money from the investor. Note that $U^{e}\left(K, r_{f}\right)=U_{\phi}^{e}$. As stated in Table 2, there is no investor who offers a lending rate lower than $r_{f}$, so there simply is no contract. Indeed, if the investor's risk premium $\mu^{i}-\kappa^{i}$ is too high relative to the preference-adjusted risk of the project $\gamma^{e} \sigma_{\pi}^{2}$, then there is no feasible contract. In this case, the venture yields an attractive risk profile for the entrepreneur (low denominator of $S^{* i}$ ), while it is costly to finance for the investor (high numerator), who then steps away.

The second situation is more insightful. The special case $\mu^{i}-\kappa^{i}=\gamma^{e} \sigma_{\pi}^{2}$ is the one where the marginal cost of the project is equal to its marginal benefit for the entrepreneur, and so she merely gives up the share of the project that she cannot finance herself. There is no transfer and thus no dilution in that particular case.

For the bank-sponsored VC, the additional condition implies that situations where the lending rate is very high or when the deposit rate is very low precludes the bank's financial intermediation. 
In those situations, any transfer would become unacceptable for the entrepreneur who would receive too little money for her deposits or would pay too much interest for her borrowing. In these cases, the only feasible contract would be the degenerate one $(1,0)$ which is feasible if $r_{\pi}-\frac{1}{2} \gamma^{e} \sigma_{\pi}^{2} \geq U_{\phi, \pi}^{e}$. Thus, this contract is much more than a curiosity, as it is likely to prevail in a wide variety of market situations.

Corollary 3 shows that the entrepreneur would prefer to contract rather than undertaking the project on her own. The rationale underlying this result is straightforward. The linear shape of the utility function of the investor enables the entrepreneur to get rid of a share of the project's risk in exchange of a proportional premium. On the other hand, the concavity of the entrepreneur's utility function provide a gain in expected utility from risk sharing which is more than proportional to the loss in returns. This implies that the presence of venture capitalists always induces the entrepreneur to seek for a risk sharing contract to get venture capital financing. Indeed, as any feasible contract satisfies the investor's participation constraint, then both the entrepreneur and the investor are better off with the contract than with their initial investment choice.

\section{Insert Figure 1 here}

Figures $1 \mathrm{a}$ and $1 \mathrm{~b}$ provide a graphical representations of the feasible contracts between the entrepreneur and the venture capitalist. In Figure 1a, the utility score of the project is not sufficient to induce the entrepreneur to shift her money away from the initial financial portfolio. The availability of a VC contract is powerful enough to shift up the expected utility, leading to a portfolio whose risk is $S^{* i} \sigma_{\pi}$ and that intersects the straight line relating $\left(0, \tau^{[i, e]}\right)$ to $\left(K \sigma_{\pi}, r_{f}+K\left(r_{\pi}-r_{f}\right)\right)$. In the investor-dominant case, the entrepreneur has access to a lending rate which is just high enough to make her indifferent with the initial financial portfolio. If the bargaining power of the entrepreneur increases, she can manage to raise her utility further, up to the moment when the investor's participation constraint becomes binding. This situation corresponds to the upper segment originating from point $\left(K \sigma_{\pi}, r_{f}+K\left(r_{\pi}-r_{f}\right)\right)$ in the figure. 
The idea put forward in Corollary 3 is best illustrated in Figure 1b. The project is attractive as it clearly stands above the Capital Market Line. If the entrepreneur could self-finance the project, she would increase her utility level, but in the absence of venture capital, she is financially constrained and can only obtain the utility score $U_{\phi}^{e}$ derived from investing on financial markets. Nevertheless, the availability of a VC contract enhances the level of expected utility, up to the maximum achievable indifference curve $U_{\max }^{e}$ corresponding to the entrepreneur-dominant contract, as shown by the arrow represented on the figure.

This finding sheds new light on the discussion provided by Schwienbacher (2007) about the entrepreneur's choice between the "just-do-it" versus the "wait-and-see" strategy. In our model, where access to the venture capital market is assumed to be readily available to the entrepreneur and the project is found to be good, the "just-do-it" (adventurous) strategy of immediately investing in the project and attracting the complement through venture capital, is indeed always the best choice. It holds irrespective of the entrepreneur's risk aversion, which can be related to the entrepreneurship style. Individuals pursuing the "wait-and-see" strategy can only do it rationally if they do not fit into our framework. This means that their decision to wait before investing in the venture would not be driven by some reluctance to share the venture's profits with an external investor, but rather by the fact that the project is not ready for investment and they could not attract a venture capitalist.

We turn to the discussion of feasible contracts and the comparison of contracts with different types of investors. This analysis of existence of feasible contracts and the comparison of contracts with different types of investors is instructive about the properties of the venture capital markets in a portfolio theory approach.

\subsection{Contracting preferences}

We first characterize the solution of the bargaining game between the entrepreneur and the investor. Next, we study the determinants of contracting preferences with the three types of investors. 


\subsubsection{Optimal contract design}

The project is specific to the entrepreneur, but there are three possible kinds of investors she can contract with. Thus, two facets characterize the optimal contract design: the choice of the contractor and the terms of the contract.

If all the bargaining power lies within the hands of the entrepreneur, she will choose to contract with the investor that enables her to maximize expected utility while binding the investor's participation constraint. Therefore, the program to maximize is

$$
U^{[e, \bar{l}]}=\max _{i=i n d, c r p, b n k}\left[U^{e}\left(S^{* i}, \tau^{[e, i]}\right)-U_{\phi, \pi}^{e}\right] \text { s.t. } U^{i}\left(S^{* i}, \tau^{[e, i]}\right)=0
$$

In the mirror case, the investor maximizes net cash flows while imposing a level of utility to the entrepreneur. If each investor competing for the same project is able to dictate the contract to the entrepreneur, the winner will be the one for whom the surplus extracted from the contract is highest. The resulting level of utility for the investor achieving the largest net return is given by:

$$
U^{[\bar{\imath}, e]}=\max _{i=i n d, c r p, b n k} U^{i}\left(S^{* i}, \tau^{[i, e]}\right) \text { s.t. } U^{e}\left(S^{* i}, \tau^{[i, e]}\right)=U_{\phi, \pi}^{e}
$$

Between these two extreme cases, the entrepreneur and each type of investor enter a bargaining game. ${ }^{12}$ We adopt the solution proposed by Fan and Sundaresan (2000) to solve for the surplus split between the entrepreneur and the investor. Specifically, denoting $\eta$ as the entrepreneur's bargaining power, and $1-\eta$ as the investor's bargaining power, the Nash solution to the bargaining game between the entrepreneur and investor $i$ is the sharing rule that maximizes the following surplus

$$
G\left(S^{* i}, \tau^{* i} ; \eta\right)=\left[U^{e}\left(S^{* i}, \tau^{* i}\right)-U_{\phi, \pi}^{e}\right]^{\eta}\left[U^{i}\left(S^{* i}, \tau^{* i}\right)\right]^{1-\eta}
$$

Note that the optimal contract design involves two objectives: (i) for a given investor, finding the optimal contract terms $\left(S^{* i}(\eta), \tau^{* i}(\eta)\right)$ as a function of the bargaining power $\eta$; and (ii) determining

\footnotetext{
${ }^{12}$ To simplify the optimal contract derivation, we abstract from competition effects that would result from interactions between multiple investors dealing with multiple entrepreneurs.
} 
the kind of investor for whom the game output is maximized. So the objective function is

$$
\max _{i=i n d, c r p, b n k} \max _{S^{* i}, \tau^{* i}} G\left(S^{* i}, \tau^{* i} ; \eta\right) .
$$

Given the optimal share of the venture determined in Proposition 2 and the range of transfer rates that corresponds to each type of investor, we can characterize the optimal contract terms and the optimal investor choice altogether, provided that there exists an interior solution for $S^{* i}$, through the following Proposition.

Proposition 4 If the entrepreneur can enter a non-degenerate venture capital contract with any type of investor, the solution of the Nash bargaining game in equation (10) with $0 \leq \eta \leq 1$ is given by

$$
\begin{aligned}
S^{* \bar{\imath}}(\eta) & =S^{* \bar{\imath}}=\frac{\mu^{\bar{\imath}}-\kappa^{\bar{\imath}}}{\gamma^{e} \sigma_{\pi}^{2}}, \\
\tau^{* \bar{\imath}}(\eta) & =\eta \tau^{[e, \bar{\imath}]}+(1-\eta) \tau^{[\bar{\imath}, e]}, \\
\bar{\imath} & =\underset{i=i n d, c r p, b n k}{\arg \max }\left(\kappa^{i}-K \mu^{i}+\frac{\left(\mu^{i}-\kappa^{i}\right)^{2}}{2 \gamma^{e} \sigma_{\pi}^{2}}\right) \text { with } \frac{\mu^{i}-\kappa^{i}}{\gamma^{e} \sigma_{\pi}^{2}}<K .
\end{aligned}
$$

In particular, $G\left(S^{* \bar{\imath}}, \tau^{* \bar{p}} ; 1\right)=U^{[e, \bar{l}]}$ and $G\left(S^{* \bar{\imath}}, \tau^{* \bar{\imath}} ; 0\right)=U^{[\bar{\imath}, e]}$.

The determinants of the optimal investor choice involves a mix of investor, project and entrepreneurrelated elements. The function to maximize provides the impact of the characteristics that differentiate investors, namely $\mu^{i}$ and $\kappa^{i}$, in case of an interior solution. It is straightforward to see that, ceteris paribus, their impact are both indeterminate on the entrepreneur's preferences, depending on the values taken by the triplet $\left(K, \gamma^{e}, \sigma_{\pi}^{2}\right)$. This result calls for a closer look at the possible contracts, as discussed hereafter. The situation where $\frac{\mu^{i}-\kappa^{i}}{\gamma^{e} \sigma_{\pi}^{2}} \geq K$ corresponds to the corner solution in which $S^{* i}=K$, where we have seen that the entrepreneur would indeed be at least as well off with her financial portfolio $\phi$.

Conditionally on the optimal investor choice, the optimal contract characteristics bear a simple and intuitive form. As the entrepreneur's proportion invested in the project is constant whatever the bargaining power, her relative strength in the negotiation shows up only in the transfer rate. Given the 
structure of the game, the equilibrium transfer rate is a weighted average of the two extreme values that bind the corresponding participation constraint. In other terms, each counterparty's share of the surplus created by the presence of a VC investor is strictly proportional to their bargaining power. Such a simple structure appears very useful in light of equation (3), that displays a linear relation between the transfer rate and the dilution factor in VC investment contracts. It is obvious that the level of entrepreneur's dilution in the ownership of the project is an indicator of her bargaining power. What Proposition 4 shows is that, knowing what is the range of dilution factors acceptable by the entrepreneur and the investor, the dilution level is directly proportional to their bargaining power.

Proposition 4 can also be viewed as a separation theorem regarding the optimal contract. It shows that the proportion of wealth invested in the project, $S^{* \bar{\imath}}$, is only a function of the investor's risk premium $\mu^{\bar{\imath}}-\kappa^{\bar{\imath}}$, the entrepreneur's risk tolerance, and project risk. This proportion is independent of $\eta$. The subsequent dilution in the entrepreneur's equity stake is only reflected in the transfer rate $\tau^{* \bar{\imath}}(\eta)$, which depends on bargaining power. Such a finding holds very strongly. It entails that, whatever the bargaining power of the entrepreneur, she will invest a larger proportion in the project if its risk is lower or if her outside wealth is larger (through a concurrent reduction in the risk aversion parameter $\gamma^{e}$ ). Bitler et al. (2005) derive a similar prediction in the context of an agency theory framework. This is also consistent with the signaling approach of Leland and Pyle (1977). But unlike both streams of research, our results are derived in a framework of symmetric and homogenous information.

Note that the expected rate of return of the venture, $r_{\pi}$, has strictly no impact on the contracting preferences. Yet, this rate is relevant as it drives the feasible character of each contract.

\subsubsection{Determinants of investor selection}

Proposition 4 provides a general framework to compare contracts with the three sources of venture capital and the initial portfolio. From Table 2, the corporate VC shares one characteristic with the other two types of investors: it bears the same cost of equity capital as the bank-sponsored VC, 
while it has access to the same riskless rate conditions as the independent VC. Thus, it is logical to perform two-by-two comparisons with the corporate venture capital fund as one branch of the alternative, the other branch being (i) the initial financial portfolio, (ii) the independent VC and (iii) the bank-sponsored VC. These comparisons are done through the following corollaries. ${ }^{13}$

Corollary 5 If the entrepreneur does not self-finance the venture, she will strictly prefer to contract with the corporate venture capital investor over her initial portfolio iff

$$
\gamma^{e}>\underline{\gamma}^{e} \equiv \frac{1-\rho_{\pi m}^{2}}{2 K\left(r_{\pi}-r_{f}-\beta_{\pi m}\left(r_{m}-r_{f}\right)\right)}\left(\frac{r_{m}-r_{f}}{\sigma_{m}}\right)^{2}
$$

This Corollary has to be interpreted together with Proposition 1 and Corollary 3. From these two results, we know that for $0<\gamma^{e} \leq \bar{\gamma}^{e}$, the entrepreneur would self-finance the venture (Proposition 1 ) but would indeed even prefer to contract with a venture capitalist (Corollary 3). On the other hand, Corollary 5 tells us that for $\gamma^{e}>\underline{\gamma}^{e}$, the entrepreneur would like to contract as well. Thus there would be no feasible contract if the project is such that $\underline{\gamma}^{e}>\bar{\gamma}^{e}$.

Corollary 6 The entrepreneur will strictly prefer to contract with the corporate over the independent venture capital investor iff

$$
\begin{cases}\mu^{i n d}<\mu^{c r p} & \text { if } \quad \frac{1}{2}\left(\mu^{i n d}+\mu^{c r p}\right)>r_{f}+K \gamma^{e} \sigma_{\pi}^{2} \\ \mu^{i n d}>\mu^{c r p} & \text { if } \quad \frac{1}{2}\left(\mu^{i n d}+\mu^{c r p}\right)<r_{f}+K \gamma^{e} \sigma_{\pi}^{2}\end{cases}
$$

Corollary 6 presents a very counter-intuitive result. To enter a contract, the entrepreneur only has to verify that her participation constraint is verified. It would be natural to expect that she would choose the investor $i$ whose cost of equity investment $\mu^{i}$ is lower, so that binding the investor's participation constraint could be done at a cheaper cost and thus the return on investment would be greater. But a lower $\mu^{i}$ induces a reduced entrepreneur's optimal stake in the venture $S^{[e, i]}$ (Proposition

\footnotetext{
${ }^{13}$ For simplicity of the exposition, we restrict the analysis to the interior solution $S^{* i}=\frac{\mu^{i}-\kappa^{i}}{\gamma^{e} \sigma_{\pi}^{2}}$. The case where $S^{* i}=K$ is not very interesting as, from Proposition 4, the analysis boils down to seeking the investor whose cost of funds $\kappa^{i}$ is the lowest.
} 
2). Therefore, $\mu^{i}$ has opposite impacts on the quantity of invested funds and the rate of return on this investment. The entrepreneur only prefers the investor with a lower cost of equity if the average risk premium for the competing venture capital investors - represented by $\frac{\left(\mu^{i n d}-r_{f}\right)+\left(\mu^{c r p}-r_{f}\right)}{2}-$ does not exceed a risk premium reflecting the risk- and preference-scaled size of the project (the product $\left.K \gamma^{e} \sigma_{\pi}^{2}\right)$. The average risk premium reflects the relative importance of the difference in costs of equity. If it is high, the absolute difference in costs of equity matters less for the entrepreneur's decision. Then, she cares more about the surplus that can be reaped, represented by the size of the project $K$. She prefers to get a higher share $S^{[e, i]}$ proposed in the optimal contract, even though the corresponding transfer rate $\tau^{[e, i]}$ is less attractive. The product $\gamma^{e} \sigma_{\pi}^{2}$ adjusts for the risk aversion of the entrepreneur. The higher the product, the less likely the choice of the investor with the greater value of $\mu^{i}$, and the more important the cost saving effect over the surplus size effect.

In a realistic setup, most projects are such that the effect of project size dominates the inequalities, so that the project risk premium exceeds the average of the investor's risk premia. In this case, the first condition of Corollary 6 holds. Furthermore, because of her disadvantage in diversification, the independent venture capital investor is likely to have a required return $\mu^{\text {ind }}$ that exceeds the one of the corporate investor. Under such circumstances, the entrepreneur has an incentive to address a corporate venture capitalist. In order to convince the entrepreneur to contract with her, the independent investor has two possibilities: (i) to reduce its cost of capital through a large diversification between the individual venture investments (i.e. reducing $\beta_{\text {ind }}$ ), or (ii) to provide an extra rate of return that compensates for the loss in expected utility resulting from the higher cost of capital.

Corollary 7 The entrepreneur will strictly prefer to contract with the corporate over the bank-sponsored venture capital investor iff

$$
\begin{aligned}
& \text { (i) } \gamma^{e} \sigma_{\pi}^{2}+r_{b d}>r_{f}+\beta_{\pi m}\left(r_{m}-r_{f}\right) \\
& \text { or (ii) } \gamma^{e} \sigma_{\pi}^{2}+r_{b l}<r_{f}+\beta_{\pi m}\left(r_{m}-r_{f}\right) \\
& \text { or (iii) } K\left(r_{\pi}-\beta_{\pi m}\left(r_{m}-r_{f}\right)\right)-(K-1) r_{f}+\frac{\left(\beta_{\pi m}\left(r_{m}-r_{f}\right)\right)^{2}}{2 \gamma^{e} \sigma_{\pi}^{2}}>r_{\pi}-\frac{1}{2} \gamma^{e} \sigma_{\pi}^{2} .
\end{aligned}
$$


Corollary 7 means that if the contract with the bank-sponsored VC fund is not degenerate (cases (i) and (ii)), then the entrepreneur would never want to contract with the bank-sponsored VC. Only if the intermediation margin $r_{b l}-r_{b d}$ is high enough, neither of these conditions is satisfied, and the bank could be freely chosen by the entrepreneur.

Unlike the independent investor studied in Corollary 6, the bank-sponsored venture capital investor does not have the possibility to weigh on its cost of capital. Thus, if the entrepreneur is dominant in the relationship, she will probably not knock on the banker's door to impose a venture capital contract. In order to induce her to enter such a contract, the banker would have to accept less favorable conditions than with another venture capital investor. This view is consistent with a dynamic view of the bankerentrepreneur relationship proposed by Hellmann (2002) in which the banker tries to lock a durable relationship in order to foster its lending opportunities.

\section{$5 \quad$ Numerical analysis}

In this section we illustrate the results implied from Proposition 4 and its Corollaries 6 and 7 . To this end, we need to rely on a base case parametrization that is discussed below.

\subsection{Calibration}

Entrepreneur's risk aversion Several contributions propose a methodology for estimating investor's attitude towards risk. But we should keep in mind that entrepreneurs should by definition be less risk averse than average individuals. Tarashev et al. (2003) show that the risk aversion coefficient implicit from S\&P options varies from 0 to 2. Bliss and Panigirtzoglou (2004) obtain a range from 0 to 4.4 , but the upper bound decreases to less than 1.3 after removing the five largest stock return volatility changes. Based on the empirical distribution of terminal payoffs from venturecapital backed projects, Hall and Woodward (2010) induce that a risk aversion coefficient of 2 makes the entrepreneur indifferent between launching the venture or not. We therefore set $\gamma^{e}=1$ for the 
base case and take a value of 2 as an upper limit for our simulations.

Market portfolio We follow Kerins et al. (2004) who estimate an annual standard deviation of S\&P500 index returns of $16.2 \%$ over the last 20 years and use a $10 \%$ market rate. Therefore, we set $r_{m}=0.1$ and $\sigma_{m}=0.16$.

Venture characteristics One way to proxy for $K$ is to divide the value of the venture's assets by the book value of entrepreneurs' equity (interpreted as their historical cost of acquisition of the project). From Bitler et al. (2005), Table II (who use National Survey of Small Businesses data), this ratio is worth 2.8 if we take mean values. It remains the same if we take median values.

Gompers and Lerner (1997) study the investments of a single venture capital firm and measure an average annual return of $30.5 \%$ gross of fees from 1972 to 1997 . Cochrane (2005) estimates the arithmetic average returns of his sample venture capital projects at $59 \%$. In their study of venture capital investments across five European countries, Manigart et al. (2002) obtain estimates of required returns from early-stage VC investments that range between $36 \%$ to $45 \%$. Accordingly, we set $r_{\pi}=$ 40\%. Kerins et al. (2004) rely on the CAPM to estimate the cost of capital for an entrepreneur. They find that the average correlation between a sample of 2,623 early stage firms' equity returns and S\&P500 returns is 0.195 . The standard deviation of their sample firms' equity returns is $102.4 \%$ (see their table 4). Consistent with these figures, the value of $\beta_{\pi m}$ is set equal to $0.2 \times 100 / 16=1.25$. Dividing the value of the standard deviation of equity returns by the average project size of 2.8 , we finally obtain $\sigma_{\pi}=35 \%$.

Cost of intermediation Demirgüç-Kunt et al. (2004) report a net interest margin for G7 countries between $2.03 \%$ (Canada) and $4.34 \%$ (the U.S.), with an unweighted average of $2.94 \%$. We use these numbers as a proxy for cost of bank intermediation, which in our model is reflected by $2\left|r_{f}-r_{b f}\right|$. Assuming a risk-free rate of $r_{f}=4 \%$, we therefore set $r_{b l}=5.5 \%$ and $r_{b d}=2.5 \%$. 
Independent venture capitalist As for the entrepreneur, Kerins et al. (2004) obtain that her average cost of capital ranges from $31.1 \%$ to $57.5 \%$ depending on her degree of commitment in the venture. Assuming these figures also apply to the partially diversified independent VC, we set $r_{f}+\beta_{\text {iind }}\left(\mu_{\text {ind }}-r_{f}\right)$ equal to $30 \%$.

Table 4 summarizes our model calibration.

Insert Table 4 here

\subsection{Feasible contracts}

Figures 2 and 3 provide numerical illustrations of Proposition 2. The upper and lower bounds for the optimal transfer are plotted against project characteristics (expected return and volatility) as well as against entrepreneur's risk aversion and project's size relative to entrepreneur's wealth. Figure 2 reports the case of the corporate VC while Figure 3 reports that of the independent VC (the case of the bank-sponsored VC is very close to that of the corporate and is therefore not reported).

Insert Figures 2 and 3 here

As expected, the higher the project volatility or the higher the entrepreneur's financial constraint, the greater room for agreement between the $\mathrm{VC}$ and the entrepreneur (i.e. the wider is the band for the optimal rate of transfer). A similar result holds for entrepreneur's risk aversion. Note however, that the space for feasible contracts does not depend on project expected return (see Figures $2 \mathrm{a}$ and 3a). Interestingly, if project size gets a bit low (see Figure $3 \mathrm{~d}$ ), then there is no more contracting possibility between the independent VC and the entrepreneur.

\subsection{Investor selection}

Figure 4 illustrates the entrepreneur's contracting preferences highlighted in Proposition 4 and Corollaries 6 and 7 as far as investor selection is concerned. Parameters are those of Table 4. For various 
degrees of entrepreneur's risk aversion, Figure 4 reports the optimal choice of venture capitalist in the space of project characteristics $\left(K, \sigma_{\pi}\right)$.

\section{Insert Figure 4 here}

Each figure produces the same type of output. Using our base-case parameterization, they show three types of tendencies: (i) corporate-backed VCs tend to be favored for the riskiest projects, especially the larger ones; (ii) independent VC funds tend to invest in the least risky projects, irrespective of their size, and in the smallest projects, irrespective of their risk; and (iii) bank-sponsored VC investors have a window of large, middle-risk projects.

Such findings are broadly in line with the empirical literature devoted to the determination of VC adequacy to project types. On a pure U.S. sample, Hellmann et al. (2008) find that bank-dependent VCs invest less often in early rounds and they engage more in larger deals than other types of VC firms. These authors posit an underlying explanation related to relationship banking. The bank-sponsored $\mathrm{VC}$ is supposed to try to invest in firms in which the entrepreneurs may demand loans in the future. In their study on a detailed sample of German VC-backed companies, Hirsch and Walz (2006) also conclude that venture capital investors that are not backed by a bank tend to finance more innovative projects. Mayer et al. (2005) carry out an empirical investigation on four countries (Germany, Israel, Japan and the U.K.). Using a granular classification of VC investor types on the basis of funding sources, they find robust evidence that corporate and independent VCs prefer to invest in early-stage projects, typically characterized by high risk and/or low size. By contrast, funds whose funding comes from banks, insurance companies and pension funds favor late-stage projects. Although each country's financial system widely differs in their sample, they do not find any evidence that these differences explain observed variations in funding sources in their sample. Note that all empirical predictions focus on the dichotomization between bank and non-bank sponsored investors. Beyond the large consistency of our predictions with this stream of literature, we also bring a rationale for a strong segmentation of project financing between corporate and independent VC funds. 
Besides evidence on project segmentation by investor type, the comparison of the graphs in Figure 4 reflects the influence of risk aversion on $\mathrm{VC}$ investor choice. The effect of an increase in the entrepreneur's risk aversion on the likelihood of contracting with the independent and corporate is clear-cut. Whatever the distribution of project size and risk, and considering the pure effect of a change in the representative entrepreneur's risk aversion, a more risk averse entrepreneur (i.e. higher $\gamma^{e}$ ) ends up being more likely to contract with a corporate VC investor than with an independent one. The impact on the bank-sponsored VC investor is less obvious. The lower and the upper bound of the zone of bank-sponsored fund contracting preference both increase with the level of risk as risk aversion increases. Therefore, if project risk is relatively high, a greater risk aversion will lead to a greater likelihood of a bank-sponsored VC implication. The opposite holds for low levels of project risk. More risk averse investors would then tend to look for an independent VC fund rather than a bank-sponsored one.

Table 5 clarifies the relation between the likelihood of contracting with the bank-sponsored VC and the entrepreneur's risk aversion for different levels of project size and risk. It shows the evolution of the relative market shares for the three types of investors as $K$ and $\sigma_{\pi}$ gradually increase. ${ }^{14}$

\section{Insert Table 5 here}

As shown in Table 5, the bank-sponsored VC market shares increase with entrepreneur's risk aversion coefficient (across all project sizes and risks) for small values of $\gamma^{e}$. However, this behavior is reversed for high values of $\gamma^{e}$.

\section{Insert Figure 5 here}

Figure 5 provides an additional illustration of Corollaries 6 and 7. It shows the difference in surplus between the corporate VC contract and the independent VC contract (Figure 5a) and between the corporate VC contract and the bank-sponsored VC contract (Figure 5b). With parameters as given as in Table 4 , we obtain $\mu^{\text {crp }}=0.115<\mu^{\text {ind }}=0.3$. As stated by Corollary 6 , the entrepreneur will

\footnotetext{
${ }^{14}$ To keep calculations simple, we assume a uniform distribution of projects across size and risk.
} 
prefer contracting with the independent $\mathrm{VC}$ as long as

$$
\frac{1}{2}\left(\mu^{i n d}+\mu^{c r p}\right)>r_{f}+K \gamma^{e} \sigma_{\pi}^{2}
$$

which is true for small values of $K$ and/or small values of $\sigma_{\pi}$. But as project size and/or project risk increase, the former condition will not hold anymore and preference will be given to the corporate VC, as shown by Figure 5a.

Similarly, parameters of Table 4 induce that $S^{*}<1$ and the bank will offer a deposit account at rate $r_{b d}$. According to Corollary 7 part (i), the entrepreneur will prefer the corporate VC contract over the bank-sponsored VC contract iff

$$
\gamma^{e} \sigma_{\pi}^{2}+r_{b d}>r_{f}+\beta_{\pi m}\left(r_{m}-r_{f}\right)
$$

which translates into a lower bound condition for project risk, as shown by Figure 5b.

Note that the magnitude of surplus difference is much smaller between the corporate VC and the bank-sponsored VC (Figure 5b) than between the corporate VC and the independent VC (Figure 5a). Combined with the empirical evidence quoted above, this might indicate that the main source of reported differences between the use of financing sources arises because of the bank-sponsored vs. independent VC dichotomy. When matched with the independent VC fund, the bank and corporate investor types look very much alike. From the pure funding cost approach that we adopt, the most adequate approach to clustering venture capital types should probably be a distinction "independent versus bank and corporate", while empirical papers have mostly adopted a "independent and corporate versus bank" type of approach.

\subsection{Dilution factor}

In this subsection we analyze the endogenous dilution factor as obtained from the optimal transfer rate from Proposition 4 and retrieved from equation (3). Figure 6 displays the dilution factor in the $(K, \sigma)$ space. As far as the base case is concerned, the venture is financed by a bank-sponsored VC 
and the optimal transfer rate is 1.34 , which is equivalent to a dilution factor of 3.07 .

Insert Figure 6 here

We see that contracting with the independent VC yields a dilution factor of one. When dealing with the bank-sponsored VC, the entrepreneur obtains a favorable (i.e. strictly greater than one) dilution factor that is convex in project size and relatively constant in project risk. Finally, with the corporate VC, the endogenous dilution factor becomes linear in both project size and project risk.

\section{Empirical analysis}

Even though they bring some geographical variety in their sample, Mayer et al. (2005) confess that their results regarding the determinants of financing choice remain puzzling in that "a large proportion of variation within as well as between countries is unrelated to sources of finance. Moreover, differences in the relation between funding source and VC activity are unrelated to the country's financial systems." A potential solution of this puzzle is provided by the link that exists between the prevailing level of risk aversion on a given market and the partitioning of investments by VC type. For the same spectrum of projects, a country in which risk aversion is stronger witnesses greater investment opportunities seized by corporate VC investors, less by independent VC investors, and more or less by bank-sponsored funds, depending on the distribution of project size and risk as discussed in the previous section.

The aim of this section is to test some of the main predictions of the model. We focus on the influence of the entrepreneur's risk aversion as this dimension has, to our knowledge, not yielded any specific predictions regarding financing choices in the literature to date. We first confront our modelinferred project characteristics with country-level evidence. Next, we investigate the link between entrepreneur's risk aversion and VC investor type contracting preferences. Finally, we analyze the model implications in terms of VC stage financing.

We carry out the analysis on a panel of European countries. Yearly fund flows between 2002 and 2009 are obtained from the European Venture Capital Association (EVCA). Thanks to the aggregation 
of country-specific data performed at the level of the EVCA, this sample benefits from a homogenous data collection methodology and classification. Furthermore, the categorization proposed by the EVCA focuses on the funding sources and not on the allocation of actual investment by VC type. The latter approach would classify funds around their organizational structure and control rights. As we differentiate investors solely on the basis of the costs of their funding sources, an organizational or control-based partitioning would not be justified.

Consistent with previous empirical evidence by Mayer et al. (2005) on European data, but also on our interpretation of bank-sponsored investors, we consider that banks, insurance companies and pension funds constitute a homogenous group under the umbrella of "bank-sponsored" investors. Independent VC investors gather sources from individuals, family offices and capital markets. Corporate VC investors encompass all other sources except the ones coming from public authorities, namely corporations, academic institutions, endowments and foundations, funds of funds, other asset managers, and others. Because governments are not counted but represent a substantial level and variability, the sum of bank-sponsored, independent and corporate VC types is inferior to one and enjoys considerable variation over country and time.

The estimation of the entrepreneur's risk aversion coefficient on each market relies on an approximation using stock market data. This approach is justifiable by the fact that the representative stock market investor's risk aversion reflects the risk attitudes of an equity investor. Even though this is presumably a strongly downward biased estimator for the overall population, it may be a reasonable proxy for the risk tolerance of the actual entrepreneur. This is the population under review in our study, since we are only interested in contracting preferences for actual venture investments. Following Bliss and Panigirtzoglou (2004), yearly risk aversion coefficients of the representative agent are estimated by regressing daily stock index returns on the changes in the daily VIX (or equivalent) implied volatility index:

$$
R_{c t} \simeq-\gamma_{c, T} \Delta V I X_{c t}+\varepsilon_{c t}
$$


where index $c$ stands for the country under consideration, $T$ is the calendar year of the regression, and $\gamma_{c, T}$ is the estimator for the representative agent's relative risk aversion coefficient. ${ }^{15}$ Daily stock market data is collected from Thomson Financial Datastream for the 2001-2009. For this time period, only seven European markets display complete and continuous series for implied volatility indices: the United Kingdom, France, Germany, Switzerland, the Netherlands, Finland and Austria. We discard the latter two countries because of too little liquidity on their stock market and lack of representativity of the venture capital investments during the period under study. The panel we create features five countries, which are the top five European countries by fundraising for the period 2005-2009. ${ }^{16}$ Taking the most active countries represents the best guarantee of having a reliable connection between the domestic market-implied risk aversion coefficient and the type of $\mathrm{VC}$ activity, be it domestic or foreign, originating from the same countries.

In order to enhance the significance of the empirical analyses, we perform the analysis on a twoyear average risk aversion coefficient, thereby losing the first observation. This leaves us with a panel of 40 observations ( 8 years $\times 5$ countries). The descriptive statistics of the sample are reported in Table 6.

\section{Insert Table 6 here}

Panel A presents the estimation results from equation (12). The results are of the same order as those of Bliss and Panigirtzoglou (2004) on U.S. data. They report a sample average of 0.40 as well. This is also in the same neighborhood, although slightly inferior, to the values obtained for the U.S., the U.K. and Germany, with a different methodology, by Tarashev et al. (2003) on a 1995-2002 time window. As expected, these values are much lower than the typical risk aversion estimates obtained in studies of the whole economy (see Bliss and Panigirtzoglou, 2004, for an overview).

\footnotetext{
${ }^{15}$ Adding an intercept to Bliss and Panigirtzoglou's initial specification improves the fit, even though its estimate is never significant in our sample. The RRA estimate reflects the absolute risk aversion coefficient for a normalized wealth of 1 , as in our setup.

${ }^{16}$ Funding sources by country of management. See the EVCA Yearbooks from 2006 to 2010 for details.
} 
Because we allocate a substantial fraction of funding sources to the bank-sponsored category, Panel B shows a dominance of that particular source of funds across time and countries. Nevertheless, we observe a large variability for all three independent variables, both cross-sectionally and over time. The correlations reported in Panel $\mathrm{C}$ indicate a large negative value between the proportion of independent invested funds, $w_{\text {ind }}$, and the risk aversion coefficient. The other correlations are moderate, except between bank and corporate VC funds, which appear largely substitutes. This observation is consistent with our analysis of surplus in the preceding section, that showed a relatively small dichotomization between these two types of funding sources regarding the level of economic gain to extract from the contract.

\subsection{Project risk and size characteristics}

As a first check of our theoretical model, we first examine the risk and size profile of VC-backed projects as a function of the country-specific level of risk aversion. Using the median value for the estimated risk aversion coefficient per country, we can use our model to retrieve the range of project risk $\left(\sigma_{\pi}\right)$ and project size $(K)$ that are consistent with the observed median shares of VC fund raising per investor type. ${ }^{17}$ Results can be visualized in Figure 7.

\section{Insert Figure 7 here}

The model predicts that the most risky projects are undertaken in the United Kingdom while the least risky ones are in the French economy. There is little variation in the project minimal size across countries. However, the biggest ventures appear to be financed in the Netherlands and in the U.K.

Next, we independently gather information on the types of usage of the funds gathered. Until 2007, the EVCA classified VC funds on the basis of "expected allocation of funds raised" by stage (early stage/expansion-development) and by technological focus (high-tech/non high-tech). We aggregate the global funding by country from 2002 to 2007. We proxy for the importance of larger size projects by

\footnotetext{
${ }^{17}$ We perform the matching under the assumption of a uniform distribution for project risk and size.
} 
using the proportion of funds directed to expansion-development projects. Likewise, the proxy for the importance of riskier projects by using, within the expansion-development projects, the proportion of funds directed to high-tech projects. The results, together with the numerical translation of Figure 7 , are reported in Table 7.

\section{Insert Table 7 here}

With such a limited sample size and as the figures result from successive approximations, it is not possible to perform statistical inference from this table. Nevertheless, the comparison of risk and size figures delivers an insightful impression of common variations. The correlation between the High-Tech

figures and the estimated upper bounds of the rectangles, $\sigma_{\pi}^{\max }$, is $26.4 \%$. Similarly, the correlation between the Expansion-Development values and $K^{\max }$ is $46.8 \%$. By contrast, the correlations between $\sigma_{\pi}^{\max }$ and Exp.-Dev. and between $K^{\max }$ and High-Tech are $-1.8 \%$ and $0.1 \%$, respectively. Even though this analysis does not constitute statistical evidence, it suggests that there could be some link between the proportions of fund sources and the types of investments performed with these funds. According to our model, this link is influenced by the level of risk aversion specific to each country. This claim is to be formally tested in the next sub-sections.

\subsection{Choice of investor type}

We now turn our attention to the direct impact of risk aversion on the choice of investor type. Naturally, the causal relationship to test is whether the entrepreneur's decision to contract with a given investor type depends on her level of risk aversion. But through a multiple regression setup, we can assess the likelihood of choosing each investor type simultaneously based upon the entrepreneur's attitude towards risk. To this end, perform a multiple linear regression of estimated risk aversion coefficients on fund flows for each type of VC.

The equation to test is

$$
\gamma_{c, T}=\gamma_{0}+\sum_{i=i n d, c r p, b n k} b_{i} w_{i ; c, T}+\text { controls }+\eta_{c, T}
$$


We run three panel regressions. The first two are basic ones without any control variable or with a single time dummy corresponding to the 2006-07 period, during which there was a significant upward jump of risk aversion across all European markets. The third panel regression accounts for potential sources of geographical heterogeneity within each investor type. We introduce interaction variables representing the product of one or several country dummies with the proportion of VC funding corresponding to each investor type: controls $=\gamma_{0}^{\prime} 1_{\left\{c=c_{1} \text { or } c_{2} \text { or } \ldots\right\}}+\sum_{i=i n d, c r p, b n k} b_{i}^{\prime} w_{i ; c, T} 1_{\left\{c=c_{1} \text { or } c_{2} \text { or } \ldots\right\}} \cdot{ }^{18}$ For each investor type, there are 30 possible combinations. Therefore, we optimize the specification by maximizing the Schwarz information criterion.

The results are reported in Table 8 . The basic panel regression results return a negative and significant coefficient for the independent VC category. This is the expected sign from the comparative statics analysis of the previous section. In all countries under consideration, there is a tendency for entrepreneurs to solicitate less funding from independent VC funds than from other sources when the risk aversion level increases. This "flight to VC safety" phenomenon does not explain, however, to whom then entrepreneurs preferably turn to. The significance level achieved from this basic regression reaches a very high level, with a panel-adjusted R-squared above $57 \%$.

\section{Insert Table 8 here}

The optimized panel regression setup enables us to account for country-specific (or zone-specific) impacts in the relation. The level and significance of the coefficient of independent VC source get stronger, and there is no country-specific effect. The coefficient corporate VC financing becomes positive, but insignificant, and with a negative country-specific adjustment for Switzerland. The most noticeable improvement comes from the bank-sponsored VC investor coefficient. We obtain a common positive and strongly significant value for France, Germany and Switzerland. ${ }^{19}$ For these countries, we emphasize a clear substitution effect from independent to bank-sponsored funds when the market risk

\footnotetext{
${ }^{18}$ Other potential determinants of risk aversion levels include the industrial structure and the proportion of foreign investments for each country. Nevertheless equation (13) does not reflect a causal relationship, and there is no theoretical reason to include such effects in the estimation.

${ }^{19}$ From our numerical analysis in Table 5, and given the range of estimated risk aversion para-
} 
aversion changes. In the Netherlands and the U.K., i.e. more market-oriented countries, there is no clear differentiation from the corporate and bank-sponsored funding source as a response to a change in entrepreneur's risk attitudes. A positive coefficient for the bank-sponsored VC fund is also in line with a quite low average project risk but high size, which is typically the type of projects that attract venture capital investment in Europe.

The significance level of this optimized regression is above $69 \%$, which is an outstanding figure given the fact that the independent variable itself results from a first-pass estimation. Therefore our results stand as strong evidence supporting our approach. They shed new light on the disappointment raised by the Mayer et al. (2005) study, because they had not specifically tested the influence of risk aversion on $\mathrm{VC}$ funding choices.

We view the reasons for this strong significance as being related to the parsimony of informational assumptions underlying our model. In our setup, the investor choice is only driven by funding cost considerations, which are readily observable. Explanations related to information asymmetries rest upon effort or added-value estimations, which are essentially forward looking and thus harder to assess. Before looking at differential effects related to these dimensions, our approach provides a background contracting framework that emphasizes core financial contracting decision criteria.

\subsection{Venture stage financing}

Although our model is one-period, it is possible to generate predictions regarding stage financing if we re-calibrate it to different phases of the venture development. There is clear evidence (see e.g. Kerins et al., 2004) that project risk decreases with the age of the venture. On the other hand, some papers document a risk of exit as the venture is completing the late stage financing and is looking for access to financial markets (see Kaplan and Strömberg, 2004, for a detailed list of examples of risks related to financial market and exit conditions). Cumming et al. (2005) for instance show that late-stage firms

meters (0.06-0.8), our model predicts a positive relation between bank-sponsored VC fund flow and entrepreneur's risk aversion. 
suffer from venture capitalists divesture when exit markets are illiquid. We therefore conjecture a U-shaped relation between project risk and development stage. In addition, we can safely assume that project size and entrepreneur's financial constraint increases with development stage. Accordingly, Figure 8 plots the paths in the space $\left(K, \sigma_{\pi}\right)$ that a venture will typically follow through its different stages.

\section{Insert Figure 8 here}

As shown by Figure 8, our model predicts that when entrepreneur's risk aversion is low, early stage will typically be financed by the corporate VC. Expansion and late stages are likely to be financed by the corporate VC also or by the bank-sponsored VC. Financing from the independent VC is unlikely, except maybe for the last stage.

By contrast, when entrepreneur's risk aversion is high, early stage will typically be financed by the independent VC. Expansion and late stages are likely to be financed by the bank-sponsored VC or by the independent VC. Financing from the corporate VC is unlikely, except maybe for the last stage.

With the same panel as before, we test whether the relative importance of investment stage in an economy at a given point in time is reflected in the weight of each investor type. We conjecture that this responsiveness depends on the prevailing level of risk aversion. The weight of different investment stage is obtained by gathering EVCA data on the expected allocation of funds raised by country and by year. We distinguish early stage, expansion-development, and every other use which is identified as late. ${ }^{20}$ We exclude LBO funds from the analysis.

We first use the full panel of data and test whether the value $w_{i ; c, T}$ depends on the risk aversion coefficient, the proportion of early stage funds, and the proportion of expansion-development funds. ${ }^{21}$ Next, we split the sample in two sub-samples of equal size based on the level of risk aversion, and perform the same regression. To control for differences in average values of risk aversion coefficient

\footnotetext{
${ }^{20}$ The EVCA provided more details about types of late-stage investments in 2008.

${ }^{21}$ We did not include the late stage proportion in the regression for collinearity reasons.
} 
from one sub-sample to the other, we center this variable around its mean. The equation to test is:

$$
w_{i ; c, T}=\text { intercept }+\lambda_{1}\left(\gamma_{c, T}-\bar{\gamma}\right)+\lambda_{2}(\text { Early Stage })_{c, T}+\lambda_{3}(\text { Exp.-Dev. })_{c, T}+\nu_{c, T} .
$$

The results of the regression are presented in Table 9 . We do not report the results for $w_{i n d ; c, T}$ as none of them are significant.

\section{Insert Table 9 here}

We mostly emphasize a substitution effect between the corporate and the bank-sponsored investor. The results for the full sample confirm that the funds originating from corporate investors are more likely to be used for early stage projects. The effect is opposite for the bank. The low risk aversion subsample does not deliver statistically significant coefficients for either investor type. However the results become very significant for the high risk aversion sub-sample. We get evidence of two phenomena: (i) the tendency to finance preferably early stage projects with corporate VC funds is reinforced, and (ii) the "flight to VC quality" emphasized before primarily leads to transacting with the bank-sponsored VC, as indicated by the signs of the risk aversion coefficients. This latter finding also explains why we find a larger tendency to prefer bank-sponsored funds when the risk aversion coefficient increases, as already evidenced in Table 8.

\section{Conclusion}

Between the fundamental risk-return trade-off analyzed in equilibrium models such as the CAPM, and the practical considerations surrounding the determination of the cost of capital for the venture capitalist and the entrepreneur, this paper has provided a theoretical building block adapted to the context of venture investments. Even though the analytical framework that we propose is relatively simple and does not require stringent assumptions, we can characterize the entrepreneurial choices and the relations with the investors in an insightful manner. We have been able to uncover a number of strong results that hold irrespective of the numerous externalities characterizing the market for 
new ventures. In particular, we emphasize the desirability of the investment relation between the entrepreneur and the venture capitalist, and the link between contracting choices and design with the cost components of the investor's capital and her bargaining power with the entrepreneur.

The theoretical model developed in this paper shows that, without entering into a cost-benefit analysis of the impact of the venture capitalist's intervention on corporate value creation, the simple risk transfer opportunity given to the entrepreneur by the venture capital relationship is powerful enough to induce her to transact with a profesional investor. Besides, we emphasize the impact that a simple market imperfection, namely differential costs of capital, can have on contract choices and design. The role of the entrepreneur's risk aversion level is particularly important in our analysis. To our knowledge, this is the first study that explicitly relates the entrepreneur's risk tolerance to her contracting choice. Such a link delivers testable hypotheses, and our tests, despite the limited sample size and the sucessful approximations made necessary by the empirical design, confirm our conjectures to a large extent. Not only this brings a potential building block on the literature analyzing the determinants of investor's choice, but it also contributes to solving a puzzle regarding the geographical variations in venture capital activity.

The limitations that this study suffers from are numerous, but they are inherent to its style and scope. As we propose a theoretical model that aims at determining equilibrium relationships, the real-life imperfections that surround the venture capital are out of its scope. We are not unaware of them however. Adverse selection and agency cost considerations affect, and probably dominate, the venture capital relationship. Frictions such as liquidity constraints and investment size or stage have a very strong impact on the venturer's investment choices and, more importantly, on the hurdle rate assigned to the portfolio. We believe that these important, but different influences do not restrain the relevance of the kind of study we propose. They simply call for a controlled empirical investigation to assess their adequacy and their practical importance. 


\section{References}

[1] Bengtsson, Ola, and Abraham S. Ravid, 2009. The geography of venture capital contracts. Working paper. Cornell University.

[2] Bengtsson, Ola, and Frederick Wang, 2010. What matters in venture capital? Evidence from entrepreneurs' stated preferences. Financial Management (forthcoming).

[3] Bitler, Marianne P., Moskowitz, Tobias J., and Annette Vissing-Jørgensen, 2005. Testing agency theory with entrepreneur effort and wealth. Journal of Finance 60, 539-576.

[4] Bliss, Robert R. and Nikolaos Panigirtzoglou, 2004. Option-implied risk aversion estimates. Journal of Finance 59, 407-446.

[5] Bottazzi, L., M. Da Rin and T. Hellmann, 2008. Who are the active investors? Evidence from venture capital. Journal of Financial Economics 89, 488-512.

[6] Brander, James A., Edward Egan, and Thomas F. Hellmann, 2008. Government sponsored versus private venture capital: Canadian evidence. NBER Working paper No. W14029. Available at SSRN: http://ssrn.com/abstract $=1137118$.

[7] Cochrane, John, 2005. The risk and return of venture capital. Journal of Financial Economics $75,3-52$.

[8] Chemmanur, T. and Z. Chen, 2006. Angels, venture capitalists, and entrepreneurs: A dynamic model of private equity financing. Working paper.

[9] Cumming, Douglas, Grant Fleming and Armin Schwienbacher, 2005. Liquidity risk and venture capital finance. Financial Management 34, 77-105.

[10] De Bettignies, J.E. and G. Chemla, 2003. Corporate venture capital: The upside of failure and competition for talent. Working paper. 
[11] Demirgüç-Kunt, Asli, Luc A. Laeven, and Ross Levine, 2004. Regulations, market structure, institutions, and the cost of financial intermediation. Journal of Money, Credit, and Banking 36, $593-622$.

[12] Fan, H. and Sundaresan, S.M., 2000. Debt valuation, renegotiation, and optimal dividend policy. Review of Financial Studies 13, 1057-1099.

[13] Garvey, Gerald T., 2001. What is an acceptable rate of return for an undiversified investor? Working paper, Peter F. Drucker Graduate School of Management, Claremont Graduate University.

[14] Goldfarb, B., G. Hoberg, D. Kirsch and A. Triantis, 2009. Does angel participation matter? An analysis of early venture financing. Working paper, Robert H. Smith School of Business, University of Maryland.

[15] Gompers, Paul, and Josh Lerner, 1997. Risk and reward in private equity investments: the challenge of performance assessment. Journal of Private Equity 1, 5-12.

[16] Gompers, Paul, and Josh Lerner, 1998. What drives venture capital fundraising? Brookings Papers on Economic Activity (Microeconomics), 149- 192.

[17] Hall, R. and Woodward, S., 2010. The burden of the nondiversifiable risk of entrepreneurship. American Economic Review 100, 1163-1194.

[18] Hellmann, Thomas., 2002. A theory of strategic venture investing. Journal of Financial Economics $62,285-314$.

[19] Hellmann, Thomas, Lindsey, Laura, and Puri, Manju, 2008. Building relationships early: Banks in venture capital. Review of Financial Studies 21, 513-541.

[20] Hellmann T. and M. Puri, 2000. The interaction between product market and financing strategy: The role of venture capital. Review of Financial Studies 13, 959-984. 
[21] Hellmann T. and M. Puri, 2002. Venture capital and the professionalization of start-up firms: Empirical evidence. Journal of Finance 57, 169-197.

[22] Hirsch J. and U. Walz, 2006. Why do contracts differ between VC types? Working paper, Center for Financial Studies, University of Frankfurt.

[23] Jääskeläinen, Mikko, Markku V. J. Maula, and Gordon C. Murray, 2007. Profit distribution and compensation structures in publicly and privately funded hybrid venture capital funds. Research Policy 36, 913-929.

[24] Kaplan, S. N. and P. Strömberg, 2004. Characteristics, contracts, and actions: Evidence from venture capitalist analyses. Journal of Finance 59, 2177-2210.

[25] Kerins, Frank, Janet Kiholm Smith, and Richard Smith, 2004. Opportunity cost of capital for venture capital investors and entrepreneurs. Journal of Financial and Quantitative Analysis 39, 385-405.

[26] Katila, R., J. D. Rosenberger, K. and M. Eisenhardt., 2008. Swimming with sharks: Technology ventures, defense mechanisms and corporate relationships. Administrative Science Quarterly 53, $195-332$

[27] Leland, Hayne E., and David H. Pyle, 1977. Informational asymmetries, financial structure, and financial intermediation. Journal of Finance 32, 371-387.

[28] Lerner, Josh, 1999. The government as venture capitalist: The long-run impact of the SBIR program. Journal of Business 72, 285-318.

[29] Manigart, Sophie, Koen De Waele, Mike Wright, Ken Robbie, Philippe Desbrières, Harry J. Sapienza, and Amy Beekman, 2002. Determinants of required return in venture capital investments: A five-country study. Journal of Business Venturing 17, 291-312 
[30] Mayer, Colin, Schoors, Koen, and Yafeh, Yshay, 2005. Sources of funds and investment activities of venture capital funds: Evidence from Germany, Israel, Japan and the United Kingdom. Journal of Corporate Finance 11, 586-608.

[31] Meulbroek, Lisa K., 2001. The efficiency of equity-linked compensation: Understanding the full cost of awarding executive stock options. Financial Management 30, 5-30.

[32] National Venture Capital Association, 2004. NVCA Yearbook. Thomson Financial, Inc.

[33] Schwienbacher, Armin, 2007. A theoretical analysis of optimal financing strategies for different types of capital-constrained entrepreneurs. Journal of Business Venturing 22, 753-781.

[34] Sørensen, Morten, 2007. How smart is smart money? A two-sided matching model of venture capital. Journal of Finance 62, 2725-2762.

[35] Subramaniam, K., 2009. A resource-based theory of corporate venture capital. Working paper, Emory University.

[36] Tarashev, N., Tsatsaronis, K. and D. Karampatos, 2003. Investors' attitude towards risk: What can we learn from options? BIS Quarterly Review June, 57-66.

[37] Ueda M., 2004. Banks versus venture capital: Project evaluation, screening, and expropriation. Journal of Finance 59, 601-621.

[38] Watson, Brian, and Josh Lerner, 2007. The public venture capital challenge: The Australian case. Available at SSRN: http://ssrn.com/abstract $=1027445$. 


\section{Appendix}

\section{Proof of Proposition 1}

The indifference point for adopting the venture is $U_{\pi}^{e}=U_{\phi}^{e}$, which yields given equations (1) and (2)

$$
2 \gamma^{e} K\left(r_{\pi}-r_{f}\right)-\gamma^{e 2} K^{2} \sigma_{\pi}^{2}=\left(\frac{\mu_{\phi}-r_{f}}{\sigma_{\phi}}\right)^{2} \text {. }
$$

Solutions are:

$$
\begin{aligned}
& \gamma_{1}^{e}=\frac{\left(r_{\pi}-r_{f}\right)-\sqrt{\left(r_{\pi}-r_{f}\right)^{2}-\sigma_{\pi}^{2}\left(\frac{\mu_{\phi}-r_{f}}{\sigma_{\phi}}\right)^{2}}}{K \sigma_{\pi}^{2}} \\
& \gamma_{2}^{e}=\frac{\left(r_{\pi}-r_{f}\right)+\sqrt{\left(r_{\pi}-r_{f}\right)^{2}-\sigma_{\pi}^{2}\left(\frac{\mu_{\phi}-r_{f}}{\sigma_{\phi}}\right)^{2}}}{K \sigma_{\pi}^{2}}
\end{aligned}
$$

The venture is self-financed for $\gamma^{e} \in\left[\gamma_{1}^{e}, \gamma_{2}^{e}\right]$. Condition $\gamma^{e}>\gamma_{1}^{e}$ is satisfied under conditions (C1) and (C2). Indeed, any real positive numbers $a$ and $b$ such that $a>b$ verify $\sqrt{a^{2}-b^{2}}>a-b$. Hence, using conditions (C1) and (C2),

$$
\gamma_{1}^{e}<\frac{\mu_{\phi}-r_{f}}{K \sigma_{\pi} \sigma_{\phi}}<\frac{\mu_{\phi}-r_{f}}{\sigma_{\phi}^{2}}=\gamma^{e}
$$

\section{Proof of Proposition 2 and Corollary 3}

First we characterize the entrepreneur's share of investment in case of any contract between $e$ and $i$. It can take two generic forms, depending on who has the bargaining power (and thus maximizes utility):

$$
\begin{aligned}
S^{* i, k_{e}} & =\underset{S}{\arg \max } U^{i}(S, \tau) \text { s.t. } U^{e}(S, \tau)=k_{e} \\
\text { or } S^{* e, k_{i}} & =\underset{S}{\arg \max } U^{e}(S, \tau) \text { s.t. } U^{i}(S, \tau)=k_{i} .
\end{aligned}
$$

Binding the constraint at $\tau^{* i, k_{e}}$ (for the first program) or $\tau^{* e, k_{i}}$ (for the second program) and replacing its value in the utility function to maximize yields

$$
\begin{aligned}
S^{* i, k_{e}} & =\underset{S}{\arg \max }\left[-k_{e}+K\left(r_{\pi}-\mu^{i}\right)+(1-S) \kappa^{i}+S \mu^{i}-\frac{1}{2} \gamma^{e} S^{2} \sigma_{\pi}^{2}\right] \\
S^{* e, k_{i}} & =\underset{S}{\arg \max }\left[-k_{i}+K\left(r_{\pi}-\mu^{i}\right)+(1-S) \kappa^{i}+S \mu^{i}-\frac{1}{2} \gamma^{e} S^{2} \sigma_{\pi}^{2}\right] .
\end{aligned}
$$


As both programs are quadratic functions of $S$ and only differ with a constant, applying the FOC yields the same value:

$$
\underset{S}{\arg }\left(\frac{\partial U^{i}\left(S, \tau^{* i, k_{e}}\right)}{\partial S}=0\right)=\underset{S}{\arg }\left(\frac{\partial U^{e}\left(S, \tau^{* e, k_{i}}\right)}{\partial S}=0\right)=\frac{\mu^{i}-\kappa^{i}}{\gamma^{e} \sigma_{\pi}^{2}}
$$

Because $U^{i}(S)$ is increasing and then decreasing, and since the value of $S$ is bounded above by $K$, we obtain the optimal level of entrepreneur's investment as

$$
S^{* i}=S^{* i, k_{e}}=S^{* e, k_{i}}=\min \left(\frac{\mu^{i}-\kappa^{i}}{\gamma^{e} \sigma_{\pi}^{2}}, K\right)
$$

The condition for the existence of an optimal contract simply follows from binding the participation constraint for the extreme cases. For the entrepreneur-dominant case, we set

$$
k_{i}=0 \Longrightarrow \tau^{[e, i]}=\kappa^{i}+\frac{K-S^{* i}}{1-S^{* i}}\left[r_{\pi}-\mu^{i}\right] .
$$

For the investor-dominant case, we get the entrepreneur's participation constraint $k_{e}=U_{\phi, \pi}^{e}=$ $\max \left(U_{\phi}^{e}, U_{\pi}^{e}\right)$ and

$$
k_{e}=U_{\phi, \pi}^{e} \Longrightarrow \tau^{[i, e]}=\frac{U_{\phi, \pi}^{e}-S^{* i} r_{\pi}+\frac{1}{2} \gamma^{e}\left(S^{* i}\right)^{2} \sigma_{\pi}^{2}}{\left(1-S^{* i}\right)} .
$$

The determination of $\mu^{i}$ and $\kappa^{i}$ for investors $i=i n d$ (the independent) and $i=\operatorname{crp}$ (the corporate) is straightforward as they can only take one value.

For investor $b n k$ (the bank-sponsored $\mathrm{VC}$ ), the function $U^{b}(S, \tau)$ is piecewise linear. So, function $U^{e}\left(S, \tau^{* b n k}\right)$, that writes

$$
U^{e}\left(S, \tau^{* b n k}\right)=\left\{\begin{array}{l}
K\left(r_{\pi}-\mu^{b n k}\right)+(1-S) r_{b l}+S\left(r_{f}+\beta_{\pi m}\left(r_{m}-r_{f}\right)\right)-\frac{1}{2} \gamma^{e} S^{2} \sigma_{\pi}^{2} \quad \text { if } S>1 \\
K\left(r_{\pi}-\mu^{b n k}\right)+(1-S) r_{b d}+S\left(r_{f}+\beta_{\pi m}\left(r_{m}-r_{f}\right)\right)-\frac{1}{2} \gamma^{e} S^{2} \sigma_{\pi}^{2} \quad \text { otherwise }
\end{array}\right.
$$

with $\mu^{b n k}>r_{b l}>r_{b d}$, is piecewise quadratic in $S$, with the same FOC as before. Three cases are to be distinguished:

(i) if $r_{f}+\beta_{\pi m}\left(r_{m}-r_{f}\right)-r_{b d}>r_{f}+\beta_{\pi m}\left(r_{m}-r_{f}\right)-r_{b l} \geq \gamma^{e} \sigma_{\pi}^{2}$, then $S^{[e, b n k]} \geq 1$ (lending situation) and the prevailing rate is $r_{b f}=r_{b l}$; 
(ii) if $\gamma^{e} \sigma_{\pi}^{2} \geq r_{f}+\beta_{\pi m}\left(r_{m}-r_{f}\right)-r_{b d}>r_{f}+\beta_{\pi m}\left(r_{m}-r_{f}\right)-r_{b l}$, then $S^{[e, b n k]} \leq 1$ (borrowing situation) and the prevailing rate is $r_{b f}=r_{b d}$;

(iii) if $r_{f}+\beta_{\pi m}\left(r_{m}-r_{f}\right)-r_{b d}>\gamma^{e} \sigma_{\pi}^{2}>r_{f}+\beta_{\pi m}\left(r_{m}-r_{f}\right)-r_{b l}$, then the local optima $S_{l}^{[e, b n k]}=$ $\frac{r_{f}+\beta_{\pi m}\left(r_{m}-r_{f}\right)-r_{b l}}{\gamma^{e} \sigma_{\pi}^{2}}<1$ and $S_{d}^{[e, b n k]}=\frac{r_{f}+\beta_{\pi m}\left(r_{m}-r_{f}\right)-r_{b d}}{\gamma^{e} \sigma_{\pi}^{2}}>1$, corresponding to the two quadratic segments of the utility function, are not compatible with the domain of $r_{b l}$ and $r_{b d}$, respectively. In this case, as $U^{e}\left(S, \tau^{* b n k}\right)$ is piecewise quadratic and has a negative coefficient in $S^{2}$, the global maximum of this function is $S^{[e, b n k]}=1$ which is a degenerate case where there is no transfer between the entrepreneur and the investor.

\section{Proof of Proposition 4}

We first solve the nested objective function

$$
\max _{S^{* i}(\eta), \tau^{* i}(\eta)} G\left(S^{* i}(\eta), \tau^{* i}(\eta) ; \eta\right)
$$

for a particular investor $i$.

First note that, from Proposition 2, the optimal entrepreneur's share in the venture is the same for any contract with a given investor, therefore $S^{* i}(\eta)=S^{* i}$. Since we assume the contract to be non-degenerate, $S^{* i}<K$. The only variable that drives the optimal contract as a function of the bargaining power is the transfer rate $\tau^{* i}$.

Taking the log of the nested objective function, applying the FOC and rearranging yields

$$
\tau^{* i}(\eta)=\arg \left\{\eta\left[U^{i}\left(S^{* i}, \tau^{* i}\right)\right]-(1-\eta)\left[U^{e}\left(S^{* i}, \tau^{* i}\right)-U_{\phi, \pi}^{e}\right]=0\right\}
$$

Equations (6) and (5) provide the values of $U^{i}$ and $U^{e}$, respectively. This gives a linear equation in $\tau^{* i}$ whose solution is given by

$$
\tau^{* i}(\eta)=\eta\left[\kappa^{i}+\frac{K-S^{* i}}{1-S^{* i}}\left(r_{\pi}-\mu^{i}\right)\right]+(1-\eta)\left[\frac{U_{\phi, \pi}^{e}-S^{* i} r_{\pi}+\frac{1}{2} \gamma^{e}\left(S^{* i}\right)^{2} \sigma_{\pi}^{2}}{1-S^{* i}}\right],
$$

where the first expression between brackets equals $\tau^{[e, i]}$ and the second one equals $\tau^{[i, e]}$ from Proposition 2. We easily check that the second order condition is satisfied. 
To solve the global problem at the equilibrium transfer rate $\tau^{* i}(\eta)$

$$
\max _{i=i n d, c r p, b n k} G\left(S^{* i}, \tau^{* i}(\eta)\right)
$$

we note that, from equation (6), and noting that $U^{i}\left(S^{* i}, \tau^{[e, i]}\right)=0$ by definition, we get:

$$
\begin{aligned}
U^{i}\left(S^{* i}, \tau^{* i}(\eta)\right)= & U^{i}\left(S^{* i}, \tau^{* i}(\eta)\right)-U^{i}\left(S^{* i}, \tau^{[e, i]}\right) \\
= & \left(K-S^{* i}\right)\left(r_{\pi}-\mu^{i}\right)-\left(1-S^{* i}\right)\left(\tau^{* i}(\eta)-\kappa^{i}\right) \\
& -\left[\left(K-S^{* i}\right)\left(r_{\pi}-\mu^{i}\right)-\left(1-S^{* i}\right)\left(\tau^{[e, i]}-\kappa^{i}\right)\right] \\
= & \left(1-S^{* i}\right)\left(\tau^{[e, i]}-\tau^{* i}(\eta)\right) \\
= & \left(1-S^{* i}\right)(1-\eta)\left(\tau^{[e, i]}-\tau^{[i, e]}\right) .
\end{aligned}
$$

Similarly, applying equation (5) and using the fact that $U_{\phi}^{e}=U^{e}\left(S^{* i}, \tau^{[i, e]}\right)$, we get

$$
\begin{aligned}
U^{e}\left(S^{* i}, \tau^{* i}(\eta)\right)-U_{\phi}^{e}= & U^{e}\left(S^{* i}, \tau^{* i}(\eta)\right)-U^{e}\left(S^{* i}, \tau^{[i, e]}\right) \\
= & \tau^{* i}(\eta)+S^{* i}\left(r_{\pi}-\tau^{* i}(\eta)\right)-\frac{1}{2} \gamma^{e}\left(S^{* i}\right)^{2} \sigma_{\pi}^{2} \\
& -\left[\tau^{[i, e]}+S^{* i}\left(r_{\pi}-\tau^{[i, e]}\right)-\frac{1}{2} \gamma^{e}\left(S^{* i}\right)^{2} \sigma_{\pi}^{2}\right] \\
= & \left(1-S^{* i}\right)\left(\tau^{* i}(\eta)-\tau^{[i, e]}\right) \\
= & \left(1-S^{* i}\right) \eta\left(\tau^{[e, i]}-\tau^{[i, e]}\right) .
\end{aligned}
$$

Hence, the global maximization problem simplifies to

$$
\max _{i=i n d, c r p, b n k} G\left(S^{* i}, \tau^{* i}(\eta)\right)=\max _{i=i n d, c r p, b n k}\left(1-S^{* i}\right)\left(\tau^{[e, i]}-\tau^{[i, e]}\right) .
$$

From the definitions of $\tau^{[e, i]}$ and $\tau^{[i, e]}$ provided in Proposition 2, the preferred investor type verifies

$$
\bar{\imath}=\underset{i=i n d, c r p, b n k}{\arg \max }\left[\kappa^{i}\left(1-S^{* i}\right)+\left(K-S^{* i}\right)\left(r_{\pi}-\mu^{i}\right)-\left(U_{\phi, \pi}^{e}-S^{* i} r_{\pi}+\frac{1}{2} \gamma^{e}\left(S^{* i}\right)^{2} \sigma_{\pi}^{2}\right)\right] .
$$

Using the fact that $S^{* i}=\frac{\mu^{i}-\kappa^{i}}{\gamma^{e} \sigma_{\pi}^{2}}$ if the contract is not degenerate, removing all terms that are independent of $i$ and rearranging yields

$$
\bar{\imath}=\underset{i=i n d, c r p, b n k}{\arg \max }\left(\kappa^{i}-K \mu^{i}+\frac{\left(\mu^{i}-\kappa^{i}\right)^{2}}{2 \gamma^{e} \sigma_{\pi}^{2}}\right),
$$

which completes the proof. 


\section{Proof of Corollaries 5, 6 and 7}

(i) To induce a shift from the entrepreneur's initial financial portfolio $\phi$ to a venture capital contract, the most favorable (i.e. entrepreneur-dominant) contract with the corporate VC must exceed the entrepreneur's participation constraint, that is:

$$
U^{e}\left(S^{[e, c r p]}, \tau^{[e, c r p]}\right)>U_{\phi, \pi}^{e}
$$

or, from Propositions 1 and 2, replacing $\mu^{c r p}=r_{f}+\beta_{\pi m}\left(r_{m}-r_{f}\right)$ and $\kappa^{c r p}=r_{f}$

$$
K\left(r_{\pi}-r_{f}-\beta_{\pi m}\left(r_{m}-r_{f}\right)\right)+\frac{1}{2 \gamma^{e}}\left(\frac{\beta_{\pi m}\left(r_{m}-r_{f}\right)}{\sigma_{\pi}}\right)^{2}>\frac{1}{2 \gamma^{e}}\left(\frac{r_{m}-r_{f}}{\sigma_{m}}\right)^{2} .
$$

By the definition of beta, we get that $\frac{\beta_{\pi m}}{\sigma_{\pi}}=\frac{\rho_{\pi m}}{\sigma_{m}}$, so the expression simplifies to

$$
\gamma^{e}>\frac{1-\rho_{\pi m}^{2}}{2 K\left(r_{\pi}-r_{f}-\beta_{\pi m}\left(r_{m}-r_{f}\right)\right)}\left(\frac{r_{m}-r_{f}}{\sigma_{m}}\right)^{2}
$$

which proves Corollary 5.

(ii) Similarly, to induce the entrepreneur to opt for the corporate VC instead of the independent VC, the following condition must be respected:

$$
U^{e}\left(S^{[e, c r p]}, \tau^{[e, c r p]}\right)>U^{e}\left(S^{[e, i n d]}, \tau^{[e, i n d]}\right),
$$

i.e.

$$
\begin{aligned}
& K\left(r_{\pi}-\mu^{c r p}\right)+r_{f}+\frac{1}{2 \gamma^{e}}\left(\frac{\mu^{c r p}-r_{f}}{\sigma_{\pi}}\right)^{2}>K\left(r_{\pi}-\mu^{i n d}\right)+r_{f}+\frac{1}{2 \gamma^{e}}\left(\frac{\mu^{i n d}-r_{f}}{\sigma_{\pi}}\right)^{2} \\
\Leftrightarrow & K\left(\mu^{i n d}-\mu^{c r p}\right)-\frac{1}{2 \gamma^{e}}\left[\left(\frac{\mu^{i n d}-r_{f}}{\sigma_{\pi}}\right)^{2}-\left(\frac{\mu^{c r p}-r_{f}}{\sigma_{\pi}}\right)^{2}\right]>0 \\
\Leftrightarrow & K\left(\mu^{i n d}-\mu^{c r p}\right)-\frac{1}{2 \gamma^{e} \sigma_{\pi}^{2}}\left[\left(\left(\mu^{i n d}-r_{f}\right)+\left(\mu^{c r p}-r_{f}\right)\right)\left(\left(\mu^{i n d}-r_{f}\right)-\left(\mu^{c r p}-r_{f}\right)\right)\right]>0 \\
\Leftrightarrow & K\left(\mu^{i n d}-\mu^{c r p}\right)-\frac{1}{2 \gamma^{e} \sigma_{\pi}^{2}}\left[\left(\left(\mu^{i n d}-r_{f}\right)+\left(\mu^{c r p}-r_{f}\right)\right)\left(\mu^{i n d}-\mu^{c r p}\right)\right]>0 \\
\Leftrightarrow & \left\{\begin{array}{cl}
r_{f}+K \gamma^{e} \sigma_{\pi}^{2}<\frac{1}{2}\left(\mu^{i n d}+\mu^{c r p}\right) & \text { if } \mu^{i n d}<\mu^{c r p} . \\
r_{f}+K \gamma^{e} \sigma_{\pi}^{2}>\frac{1}{2}\left(\mu^{i n d}+\mu^{c r p}\right) & \text { if } \mu^{i n d}>\mu^{c r p}
\end{array}\right.
\end{aligned}
$$

(iii) Finally, to induce the entrepreneur to opt for the corporate VC instead of the bank-sponsored VC, the following condition must be respected:

$$
U^{e}\left(S^{[e, c r p]}, \tau^{[e, c r p]}\right)>U^{e}\left(S^{[e, b n k]}, \tau^{[e, b n k]}\right)
$$


Three cases have to be distinguished:

Case 1: $\gamma^{e} \sigma_{\pi}^{2}+r_{b d}>r_{f}+\beta_{\pi m}\left(r_{m}-r_{f}\right)$. Then, from Proposition 2, $S^{[e, b n k]}=\frac{\mu^{b n k}-\kappa^{b n k}}{\gamma^{e} \sigma_{\pi}^{2}}<1$ and $r_{b f}=r_{b d}$. The condition writes:

$$
\begin{aligned}
& K\left(r_{\pi}-\mu^{c r p}\right)+r_{f}+\frac{1}{2 \gamma^{e}}\left(\frac{\mu^{c r p}-r_{f}}{\sigma_{\pi}}\right)^{2}>K\left(r_{\pi}-\mu^{b n k}\right)+r_{b d}+\frac{1}{2 \gamma^{e}}\left(\frac{\mu^{b n k}-r_{b d}}{\sigma_{\pi}}\right)^{2} \\
\Leftrightarrow & r_{f}-r_{b d}-\frac{1}{2 \gamma^{e}}\left[\left(\frac{\mu^{i n d}-r_{b d}}{\sigma_{\pi}}\right)^{2}-\left(\frac{\mu^{b n k}-r_{f}}{\sigma_{\pi}}\right)^{2}\right]>0 \\
\Leftrightarrow & r_{f}-r_{b d}-\frac{1}{2 \gamma^{e} \sigma_{\pi}^{2}}\left[\left(\left(\mu^{b n k}-r_{b d}\right)+\left(\mu^{c r p}-r_{f}\right)\right)\left(\left(\mu^{b n k}-r_{b d}\right)-\left(\mu^{c r p}-r_{f}\right)\right)\right]>0 \\
\Leftrightarrow & r_{f}-r_{b d}-\frac{1}{2 \gamma^{e} \sigma_{\pi}^{2}}\left[\left(\left(\mu^{b n k}-r_{b d}\right)+\left(\mu^{c r p}-r_{f}\right)\right)\left(r_{f}-r_{b d}\right)\right]>0 \\
\Leftrightarrow & 1-\frac{1}{\gamma^{e} \sigma_{\pi}^{2}}\left[r_{f}+\beta_{\pi m}\left(r_{m}-r_{f}\right)-\frac{1}{2}\left(r_{f}+r_{b d}\right)\right]>0 . \\
\Leftrightarrow & 1-\frac{1}{2}\left(S^{[e, b n k]}+S^{[e, c r p]}\right)>0
\end{aligned}
$$

which is always true as $S^{[e, c r p]}<S^{[e, b n k]}<1$.

Case 2: $\gamma^{e} \sigma_{\pi}^{2}+r_{b l}<r_{f}+\beta_{\pi m}\left(r_{m}-r_{f}\right)$. Then $S^{[e, b n k]}=\frac{\mu^{b n k}-\kappa^{b n k}}{\gamma^{e} \sigma_{\pi}^{2}}>1$ and $r_{b f}=r_{b l}$. The proof is similar to the one of Case 1.

Case 3: $\gamma^{e} \sigma_{\pi}^{2}+r_{b d}<r_{f}+\beta_{\pi m}\left(r_{m}-r_{f}\right)<\gamma^{e} \sigma_{\pi}^{2}+r_{b l}$. From Proposition 2, the contract with the bank-sponsored VC is degenerate with $S^{[e, b n k]}=1$ and $U^{e}\left(S^{[e, b n k]}, \tau^{[e, b n k]}\right)=r_{\pi}-\frac{1}{2} \gamma^{e} \sigma_{\pi}^{2}$. The expression follows. 


\section{Tables}

Table 1: Characteristics of investor types.

\begin{tabular}{lccc}
\hline \hline Type of venture capital sponsor & Independent & Corporate & Bank \\
\cline { 2 - 4 } Profit-maximizer & $\checkmark$ & $\checkmark$ & $\checkmark$ \\
Diversified shareholders & $\times$ & $\checkmark$ & $\checkmark$ \\
Financial intermediary & $\times$ & $\times$ & $\checkmark$ \\
\hline \hline
\end{tabular}


Table 2: Shares in total funds raised by investor type in the U.S. and Europe.

\begin{tabular}{llll}
\hline \hline Classification & Investor type & U.S. (\%) & Europe (\%) \\
"Corporate" & Funds of funds & & 18.8 \\
& Endowments and foundations & 21.0 & 3.3 \\
& Corporate Investors & 2.0 & 5.9 \\
& Total & $\mathbf{2 3 . 0}$ & $\mathbf{2 8 . 0}$ \\
"Bank-sponsored" & Banks & 25.0 & 21.6 \\
& Insurance companies & & 13.0 \\
& Pension funds & 42.0 & 28.8 \\
& Total & $\mathbf{6 7 . 0}$ & $\mathbf{6 3 . 4}$ \\
"Independent" & Private Individuals & $\mathbf{1 0 . 0}$ & $\mathbf{8 . 6}$ \\
\hline \hline
\end{tabular}

Source: The European Venture Capital Association (EVCA) and the National Venture Capital Association (NVCA). Funding sources coming from government agencies and unidentified sources were left out. U.S. data are for year 2003. European data are for years 2002-2006 (average). 
Table 3: Characteristics of investors' utility maximization.

\begin{tabular}{ccc}
\hline \hline & $\mu^{i}$ & $\kappa^{i}$ \\
\hline Corporate & $r_{f}+\beta_{\pi m}\left(r_{m}-r_{f}\right)$ & $r_{f}$ \\
Independent & $r_{f}+\beta_{\pi i n d}\left(r_{i n d}-r_{f}\right)$ & $r_{f}$ \\
Bank & $r_{f}+\beta_{\pi m}\left(r_{m}-r_{f}\right)$ & $r_{b d}$ or $r_{b l}$ \\
\hline \hline
\end{tabular}

Note: $\mu^{i}$ represents the cost of equity investment. $\kappa^{i}$ represents the rate of lending (if $S>1$ ) or borrowing (if $S<1$ ) available to the investor. 
Table 4: List of calibrated parameters.

\begin{tabular}{llcc}
\hline \hline & Parameter & Notation & Value \\
\hline Entrepreneur & Risk aversion coefficient & $\gamma^{e}$ & $1^{*}$ \\
\hline Market portfolio & Expected return & $r_{m}$ & 0.10 \\
& Standard deviation & $\sigma_{m}$ & 0.16 \\
\hline Venture & Expected return & $r_{\pi}$ & $0.40^{*}$ \\
& Standard deviation & $\sigma_{\pi}$ & $0.35^{*}$ \\
& Beta & $\beta_{\pi m}$ & 1.25 \\
& Size & $K$ & $3^{*}$ \\
\hline Cost of intermediation & Risk-free rate & $r_{f}$ & 0.04 \\
& Bank loan rate & $r_{b l}$ & 0.055 \\
& Bank deposit rate & $r_{b d}$ & 0.025 \\
\hline Independent VC & Cost of capital & $\mu^{i n d}$ & 0.30 \\
\hline \hline
\end{tabular}

Table 4 summarizes the base case calibration. Risk aversion coefficient is made consistent with estimates from Tarashev et al. (2003), Bliss and Panigirtzoglou (2004) as well as Hall and Woodward (2010). Market portfolio parameters are derived from Kerins et al. (2004). Venture characteristics are obtained from Bitler et al. (2005), Gompers and Lerner (1997), Cochrane (2005), Manigart et al. (2002) as well as Kerins et al. (2004). Cost of intermediation is inferred from Demirgüç-Kunt et al. (2004). Cost of capital for the independent venture capital is obtained from Kerins et al. (2004). Parameters marked with a star are varying in our simulations analysis. 
Table 5: Market share changes for the bank-sponsored VC investor.

\begin{tabular}{lccccc}
\hline \hline \multicolumn{7}{c}{ Panel A: Risk aversion coefficient shifts from 0.1 to 1} \\
\hline \multicolumn{7}{c}{$K \leq 2$} & $K \leq 3$ & $K \leq 4$ & $K \leq 5$ & $K \leq 6$ \\
\hline$\sigma_{\pi} \leq 0.1$ & 0 & 0 & 0 & 0 & 0 \\
$\sigma_{\pi} \leq 0.2$ & 0 & 0 & 0 & +0.013 & +0.039 \\
$\sigma_{\pi} \leq 0.3$ & 0 & +0.049 & +0.113 & +0.167 & +0.213 \\
$\sigma_{\pi} \leq 0.4$ & 0 & +0.036 & +0.084 & +0.125 & +0.158 \\
$\sigma_{\pi} \leq 0.5$ & 0 & +0.029 & +0.067 & +0.099 & +0.126 \\
\hline Panel B: Risk aversion coefficient shifts from 1 to 2 \\
\hline \multicolumn{7}{c}{$K \leq 2$} & $K \leq 3$ & $K \leq 4$ & $K \leq 5$ & $K \leq 6$ \\
\hline$\sigma_{\pi} \leq 0.1$ & 0 & 0 & 0 & 0 & 0 \\
$\sigma_{\pi} \leq 0.2$ & 0 & +0.046 & +0.112 & +0.157 & +0.178 \\
$\sigma_{\pi} \leq 0.3$ & 0 & -0.014 & -0.033 & -0.049 & -0.062 \\
$\sigma_{\pi} \leq 0.4$ & 0 & -0.010 & -0.024 & -0.036 & -0.046 \\
$\sigma_{\pi} \leq 0.5$ & 0 & -0.008 & -0.019 & -0.029 & -0.037 \\
\hline \hline
\end{tabular}

This table reports the change in the number of instances where the optimal investor type is the banksponsored VC as entrepreneur risk aversion coefficient shifts from 0.1 to 1 (Panel A) and from 1 to 2 (Panel B). Calculations are made under the assumption of a uniform distribution across project size and risk. Parameter values are in Table 4. 
Table 6: Descriptive statistics of empirical variables.

\begin{tabular}{cccccc}
\hline \hline \multicolumn{6}{c}{ Panel A: Dependent Variable } \\
\cline { 2 - 5 }$c$ & \multicolumn{5}{c}{$\gamma_{c, T}$} \\
nyean & med. & s.d. & range & $\bar{R}^{2}$ \\
FR & 0.57 & 0.65 & 0.17 & $0.30-0.80$ & $41.29 \%$ \\
GE & 0.37 & 0.38 & 0.19 & $0.06-0.67$ & $29.34 \%$ \\
NL & 0.33 & 0.34 & 0.15 & $0.06-0.52$ & $25.50 \%$ \\
SW & 0.42 & 0.37 & 0.11 & $0.29-0.59$ & $36.00 \%$ \\
UK & 0.33 & 0.33 & 0.13 & $0.07-0.47$ & $32.38 \%$ \\
\hline Total & 0.40 & 0.39 & 0.17 & $0.06-0.80$ & $33.80 \%$ \\
\hline \hline
\end{tabular}

\begin{tabular}{|c|c|c|c|c|c|c|c|c|c|c|c|c|}
\hline \multicolumn{13}{|c|}{ Panel B: Independent Variables } \\
\hline \multirow[b]{2}{*}{$c$} & \multicolumn{4}{|c|}{$w_{i n d ; c, T}$} & \multicolumn{4}{|c|}{$w_{c r p ; c, T}$} & \multicolumn{4}{|c|}{$w_{b n k ; c, T}$} \\
\hline & mean & med. & s.d. & range & mean & med. & s.d. & range & mean & med. & s.d. & range \\
\hline FR & 0.13 & 0.12 & 0.06 & $0.06-0.25$ & 0.19 & 0.18 & 0.07 & $0.09-0.35$ & 0.49 & 0.50 & 0.15 & $0.25-0.65$ \\
\hline GE & 0.12 & 0.08 & 0.09 & $0.02-0.28$ & 0.20 & 0.17 & 0.12 & $0.08-0.47$ & 0.45 & 0.52 & 0.14 & $0.21-0.63$ \\
\hline NL & 0.07 & 0.06 & 0.06 & $0.00-0.21$ & 0.25 & 0.30 & 0.13 & $0.06-0.43$ & 0.61 & 0.58 & 0.18 & $0.29-0.84$ \\
\hline SW & 0.15 & 0.10 & 0.19 & $0.00-0.55$ & 0.35 & 0.30 & 0.21 & $0.07-0.74$ & 0.38 & 0.38 & 0.18 & $0.06-0.66$ \\
\hline UK & 0.07 & 0.07 & 0.03 & $0.03-0.12$ & 0.25 & 0.24 & 0.03 & $0.20-0.28$ & 0.50 & 0.49 & 0.09 & $0.38-0.68$ \\
\hline Total & 0.11 & 0.11 & 0.10 & $0.00-0.55$ & 0.25 & 0.25 & 0.14 & $0.06-0.74$ & 0.49 & 0.49 & 0.16 & $0.06-0.84$ \\
\hline
\end{tabular}

\begin{tabular}{|c|c|c|c|}
\hline \multicolumn{4}{|c|}{ Panel C: Correlations } \\
\hline & $\gamma_{c, T}$ & $w_{i n d ; c, T}$ & $w_{\text {crp } ; c, T}$ \\
\hline$w_{\text {ind;c,T }}$ & $-0.50^{* * *}$ & 1 & \\
\hline$w_{c r p ; c, T}$ & $-0.33^{* *}$ & 0.16 & 1 \\
\hline$w_{b n k ; c, T}$ & 0.21 & -0.26 & $-0.47^{* * *}$ \\
\hline
\end{tabular}

This table reports the descriptive statistics of the dependent variable (Panel A) and independent variable (Panel B) for France (FR), Germany (GE), the Netherlands (NL), Switzerland (SW) and United Kingdom (UK) for the period 2001-2009 (Panel A) and 2002-2009 (Panel B). The yearly estimate of $\gamma_{c, T}$ is obtained by regression $R_{c, t} \simeq a-\gamma_{c, T} \Delta V I X_{c t}+\varepsilon_{c t}$ on daily data. In Panel $\mathrm{A}$, the last columns reports the average $\mathrm{R}$ squared from the individual yearly regressions. In Panel C, superscripts ${ }^{*},{ }^{* *},{ }^{* * *}$ indicate statistically significant at the $10 \%, 5 \%$ and $1 \%$ confidence level, respectively. 
Table 7: Project risk and size characteristics per country.

\begin{tabular}{lccccc}
\hline \hline & \multicolumn{2}{c}{ Project risk } & & \multicolumn{2}{c}{ Project size } \\
\cline { 2 - 3 } \cline { 5 - 6 } Country & {$\left[\sigma_{\pi}^{\min }, \sigma_{\pi}^{\max }\right]$} & High-Tech & & $\left.K^{\min }, K^{\max }\right]$ & Exp./Dev. \\
\hline FR & {$[0.306,0.371]$} & 0.306 & & {$[1.91,4.27]$} & 0.634 \\
GE & {$[0.433,0.475]$} & 0.288 & & {$[1.95,3.81]$} & 0.643 \\
NL & {$[0.410,0.531]$} & 0.490 & & {$[1.95,7.09]$} & 0.738 \\
SW & {$[0.435,0.499]$} & 0.817 & & {$[1.74,4.43]$} & 0.329 \\
UK & {$[0.439,0.526]$} & 0.248 & & {$[1.84,5.89]$} & 0.629 \\
\hline \hline
\end{tabular}

This table reports, between brackets, the estimated range for project risk and project size that is consistent with observed median VC fund raising shares per investor type. Results are obtained for France (FR), Germany (GE), the Netherlands (NL), Switzerland (SW) and the United Kingdom (UK) for the period 2002-2009. The range determination assumes a uniform distribution across project risk and project size. The High-Tech column reports the aggregate proportion of VC funds that were expected by EVCA to be used in high-tech companies for their expansion or development from 2002 to 2007. The Exp./Dev. column reports the aggregate proportion of VC funds that were expected by EVCA to be used for the expansion or development of VC-backed companies from 2002 to 2007. 
Table 8: Panel multiple regression of risk aversion on investor types.

\begin{tabular}{|c|c|c|c|c|c|c|c|}
\hline \multirow{5}{*}{$\begin{array}{c}\text { Basic Panel } \\
\text { Regression }\end{array}$} & & $\gamma_{0}$ & $w_{\text {ind } ; c, T}$ & $w_{c r p ; c, T}$ & $w_{b n k ; c, T}$ & $\bar{c}$ & $\overline{\overline{\bar{R}^{2}}}$ \\
\hline & & $0.393^{* * *}$ & $-0.554^{* *}$ & -0.069 & 0.127 & & $57.47 \%$ \\
\hline & & $(0.126)$ & $(0.236)$ & $(0.197)$ & $(0.141)$ & & \\
\hline & & $0.340^{* *}$ & $-0.522^{* *}$ & -0.056 & 0.181 & $0.076^{* *}$ & $59.52 \%$ \\
\hline & & $(0.076)$ & $(0.234)$ & $(0.175)$ & $(0.164)$ & $(0.030)$ & \\
\hline \multirow{10}{*}{$\begin{array}{c}\text { Optimized } \\
\text { Panel } \\
\text { Regression }\end{array}$} & Pool & $0.231^{* *}$ & $-0.559^{* * *}$ & 0.230 & $0.392^{* * *}$ & $0.105^{* * *}$ & $69.26 \%$ \\
\hline & & $(0.103)$ & $(0.117)$ & $(0.211)$ & $(0.115)$ & $(0.028)$ & \\
\hline & $\mathrm{FR}$ & $0.410^{* * *}$ & & & & & \\
\hline & & $(0.097)$ & & & & & \\
\hline & NL & & & & 0.083 & & \\
\hline & & & & & $(0.088)$ & & \\
\hline & SW & & & -0.212 & & & \\
\hline & & & & $(0.165)$ & & & \\
\hline & UK & & & & 0.083 & & \\
\hline & & & & & $(0.088)$ & & \\
\hline
\end{tabular}

This table reports the panel least squares regression coefficients for the generic equation $\gamma_{c, T}=\gamma_{0}+$ $\sum_{i=i n d, c r p, b n k} b_{i} w_{i ; c, T}+$ controls $+\eta_{c, T}$ estimated with yearly data on France (FR), Germany (GE), the Netherlands (NL), Switzerland (SW) and the United Kingdom (UK) for the period 2002-2009. Standard deviations are reported between parentheses. The dummy variable $d_{0607}$ takes value 1 if the year is 2006 or 2007 and 0 otherwise. The other control variables have the structure controls $=\gamma_{0}^{\prime} 1_{\left\{c=c_{1} \text { or } c_{2} \text { or... }\right\}}+$

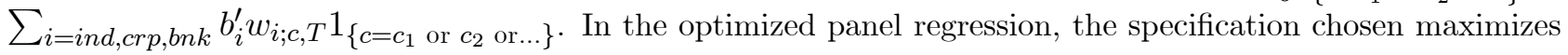
the Schwarz information criterion. For each country specific coefficient, significance is assessed on the net coefficient value $\gamma_{0}+\gamma_{0}^{\prime}$ or $b_{i}+b_{i}^{\prime}$ using the Wald test. Superscripts ${ }^{*},{ }^{* *},{ }^{* *}$ indicate statistically significant at the $10 \%, 5 \%$ and $1 \%$ confidence level, respectively. 
Table 9: Relation between investor type and financing stage.

\begin{tabular}{|c|c|c|c|c|c|c|}
\hline \multirow{4}{*}{ Corporate } & & intercept & $\overline{\gamma_{c, T}-\bar{\gamma}}$ & Early stage & Exp.-Dev. & $\overline{\overline{R^{2}}}$ \\
\hline & Full sample & $\begin{array}{c}0.256^{* * *} \\
(0.068)\end{array}$ & $\begin{array}{c}-0.224 \\
(0.152)\end{array}$ & $\begin{array}{c}0.378^{* * *} \\
(0.114)\end{array}$ & $\begin{array}{c}-0.140 \\
(0.092)\end{array}$ & $32.66 \%$ \\
\hline & Low RA & $\begin{array}{c}0.337^{* * *} \\
(0.106)\end{array}$ & $\begin{array}{c}0.201 \\
(0.402)\end{array}$ & $\begin{array}{c}0.258 \\
(0.163)\end{array}$ & $\begin{array}{l}-0.195 \\
(0.132)\end{array}$ & $30.80 \%$ \\
\hline & High RA & $\begin{array}{l}0.178^{*} \\
(0.094)\end{array}$ & $\begin{array}{c}-0.504^{*} \\
(0.290)\end{array}$ & $\begin{array}{c}0.452^{* *} \\
(0.166)\end{array}$ & $\begin{array}{l}-0.046 \\
(0.142)\end{array}$ & $33.30 \%$ \\
\hline \multirow{3}{*}{ Bank } & Full sample & $\begin{array}{c}0.533^{* * *} \\
(0.081)\end{array}$ & $\begin{array}{c}0.207 \\
(0.180)\end{array}$ & $\begin{array}{c}-0.222^{*} \\
(0.134)\end{array}$ & $\begin{array}{l}0.215^{* *} \\
(0.108)\end{array}$ & $19.98 \%$ \\
\hline & Low RA & $\begin{array}{c}0.492^{* * *} \\
(0.128)\end{array}$ & $\begin{array}{r}-0.026 \\
(0.488)\end{array}$ & $\begin{array}{c}-0.124 \\
(0.199)\end{array}$ & $\begin{array}{c}0.236 \\
(0.160)\end{array}$ & $10.29 \%$ \\
\hline & High RA & $\begin{array}{c}0.596^{* * *} \\
(0.109)\end{array}$ & $\begin{array}{c}0.606^{*} \\
(0.337)\end{array}$ & $\begin{array}{c}-0.306^{*} \\
(0.193)\end{array}$ & $\begin{array}{c}0.127 \\
(0.165)\end{array}$ & $21.14 \%$ \\
\hline
\end{tabular}

This table reports the ordinary least squares regression coefficients for the generic regression equation $w_{i ; c, T}=$ intercept $+\lambda_{1}\left(\gamma_{c, T}-\bar{\gamma}\right)+\lambda_{2}$ (Early Stage $)_{c, T}+\lambda_{3}$ (Exp.-Dev. $)_{c, T}+\nu_{c, T}$ estimated with yearly data on France (FR), Germany (GE), the Netherlands (NL), Switzerland (SW) and the United Kingdom (UK) for the period 2002-2009. Standard deviations are reported between parentheses. The Low RA and High RA sub-samples correspond to the 20 country-year observations with lowest and highest risk aversion coefficients, respectively. Superscripts ${ }^{* * *},{ }^{* * *}$ indicate statistically significant at the $10 \%, 5 \%$ and $1 \%$ confidence level, respectively. 


\section{Figures}

\section{Figure 1: Feasible contracts.}

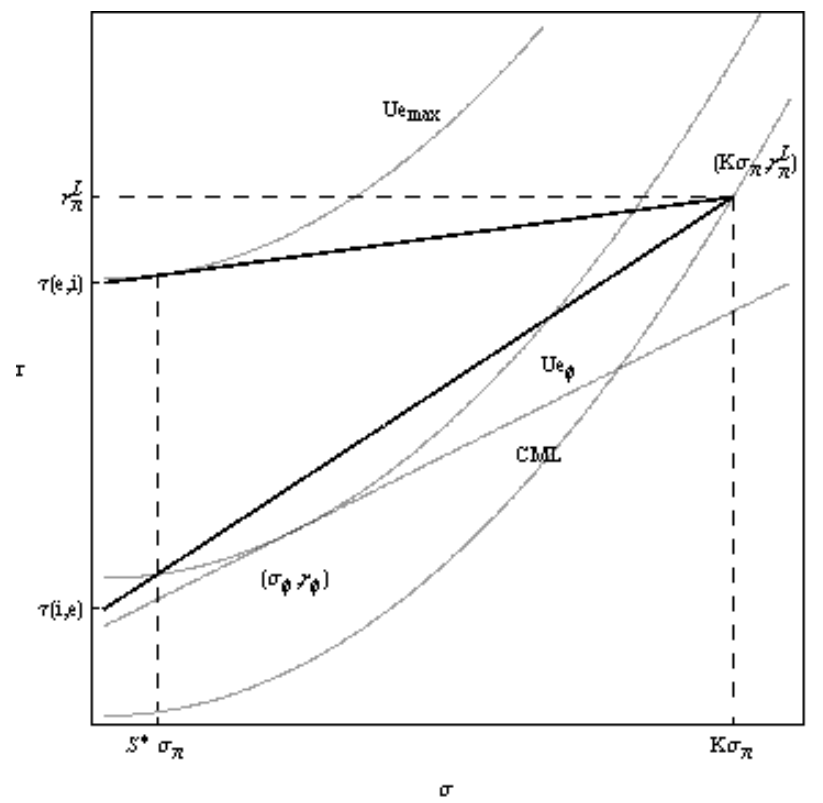

Figure 1a

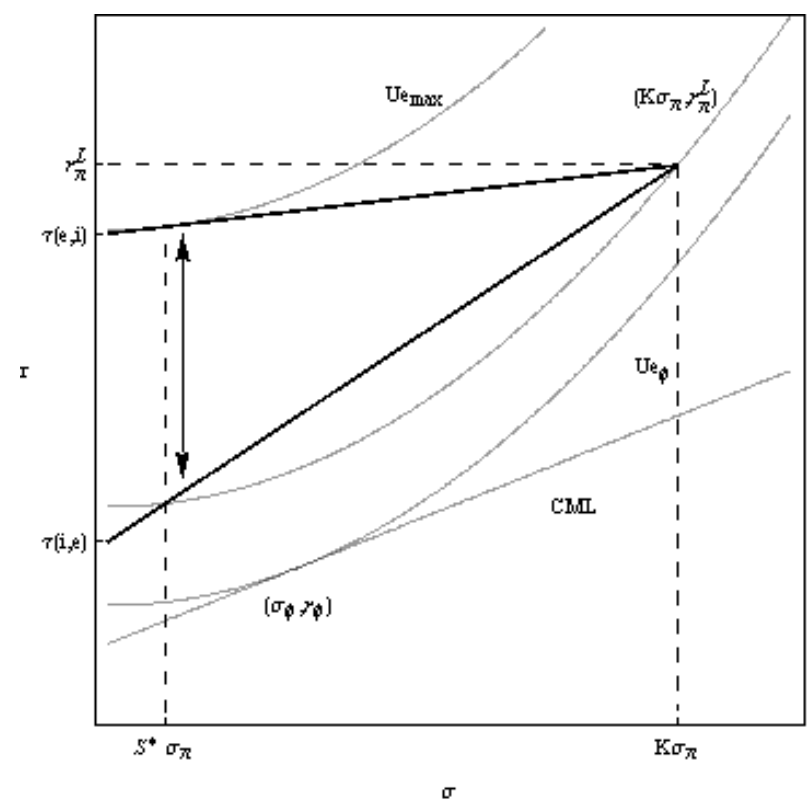

Figure $1 \mathrm{~b}$

Figures $1 \mathrm{a}$ and $1 \mathrm{~b}$ illustrate the feasible contracts between the entrepreneur and the venture capitalist in the standard deviation - mean space when the entrepreneur does not (figure 1a) or does (figure 1b) finance the venture. The curve labeled $U_{\phi}^{e}$ is the entrepreneur's initial utility function. The straight line labeled CML is the Capital Market Line. Their tangency point is at coordinates $\left(\sigma_{\phi}, \mu_{\phi}\right)$. The bold straight lines connect the project characteristics $\left(K \sigma_{\pi}, r_{\pi}^{L}\right)$, where $r_{\pi}^{L} \equiv r_{f}+K\left(r_{\pi}-r_{f}\right)$ denotes the project's levered return, with the lower and upper bounds for the admissible rate of transfer between the entrepreneur and the venture capitalist $\left(\tau^{[e . i]}\right.$ and $\left.\tau^{[i, e]}\right)$. The arrow in figure $1 \mathrm{~b}$ spans the possible utility gains for the entrepreneur resulting from all feasible contracts. 


\section{Figure 2: Bounds for rate of transfer - corporate VC case.}

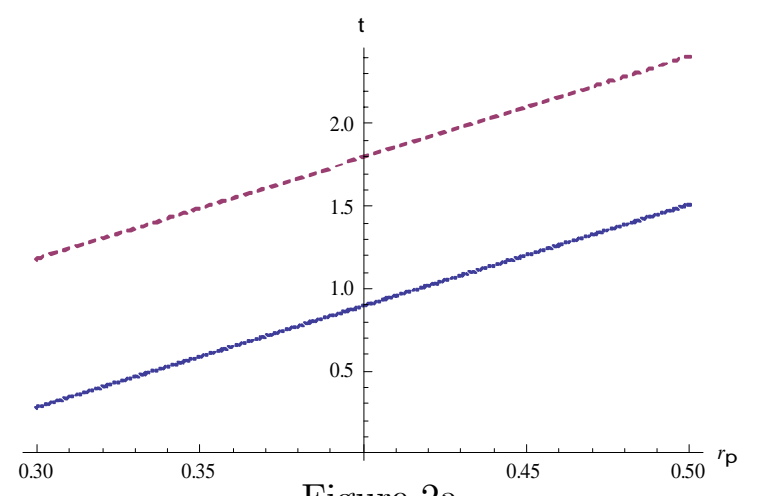

Figure 2a

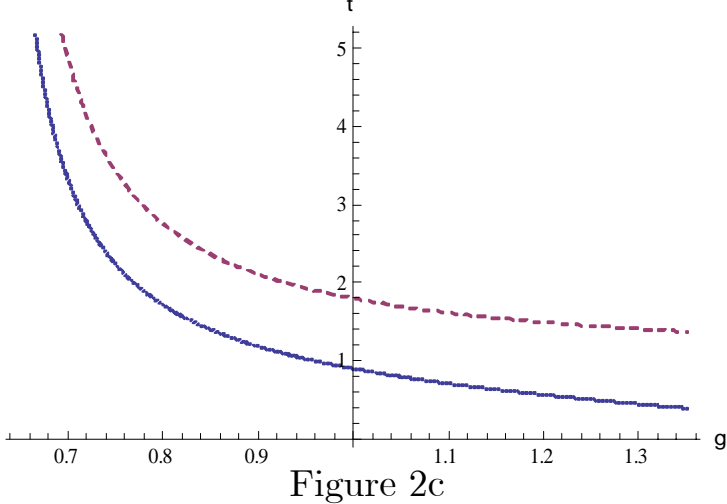

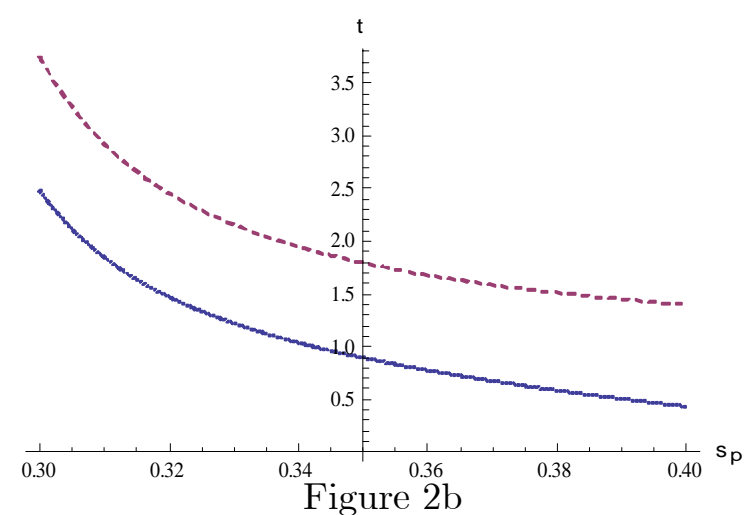

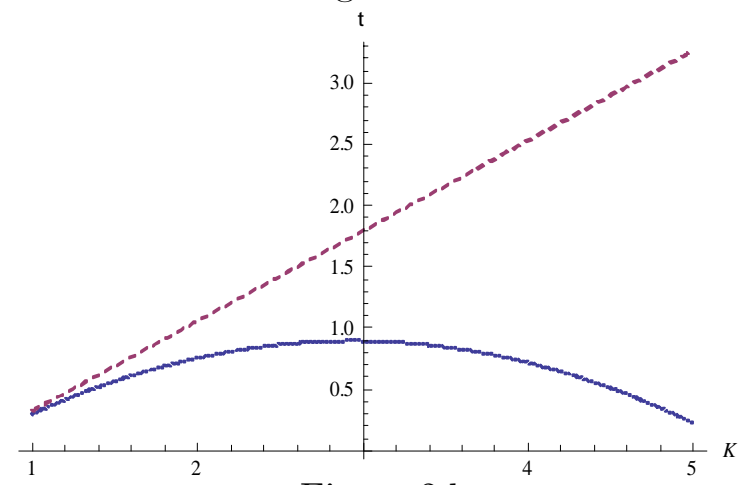

Figure 2d

Figures 2a to $2 \mathrm{~d}$ plot $\tau^{[i, e]}$ (straight line) and $\tau^{[e, i]}$ (dashed line) as a function of project expected return $r_{\pi}$ (figure 2a), project return volatility $\sigma_{\pi}$ (figure $2 \mathrm{~b}$ ), entrepreneur's risk aversion $\gamma^{e}$ (figure 2c) and project's size relative to entrepreneur's wealth $K$ (figure $2 \mathrm{~d}$ ). Base case parameter values are in Table 4 . The $y$-axis is positioned at the base case value. The type of venture capital is corporate. In all the plotted domains, endogenous $S^{*}$ is below 1 , hence a contract is feasible when $\tau^{[i, e]}<\tau^{[e, i]}$. 
Figure 3: Bounds for rate of transfer - independent VC case.

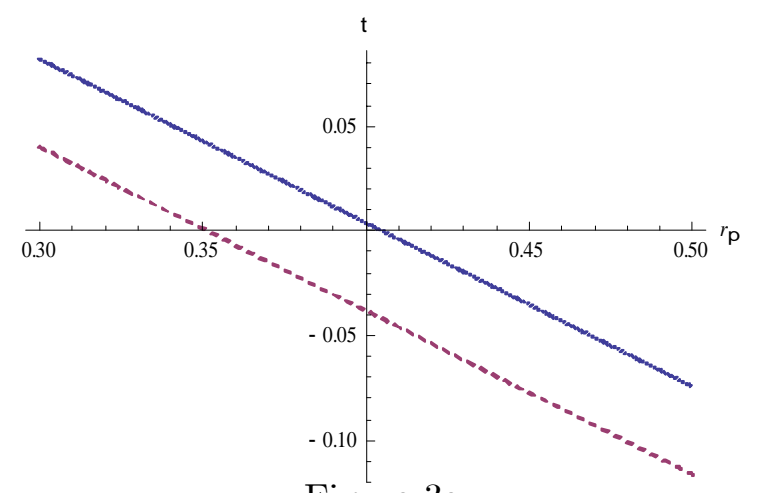

Figure 3a

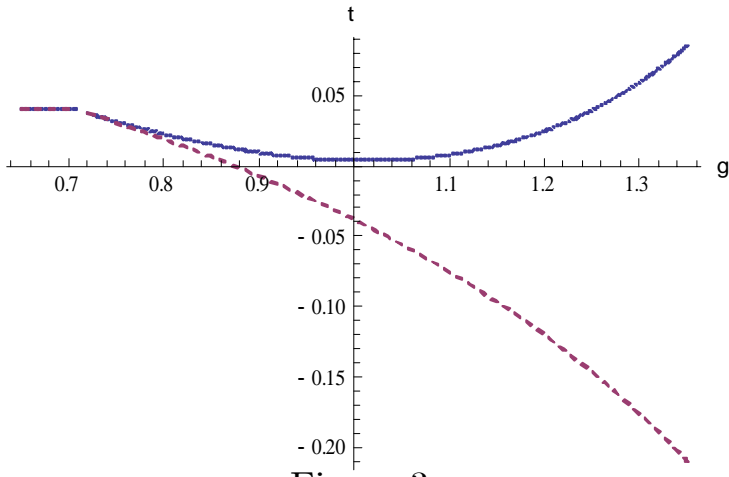

Figure 3c

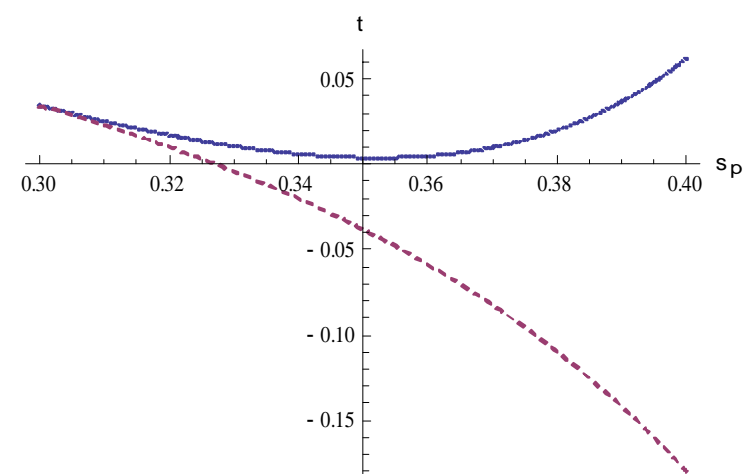

Figure 3b

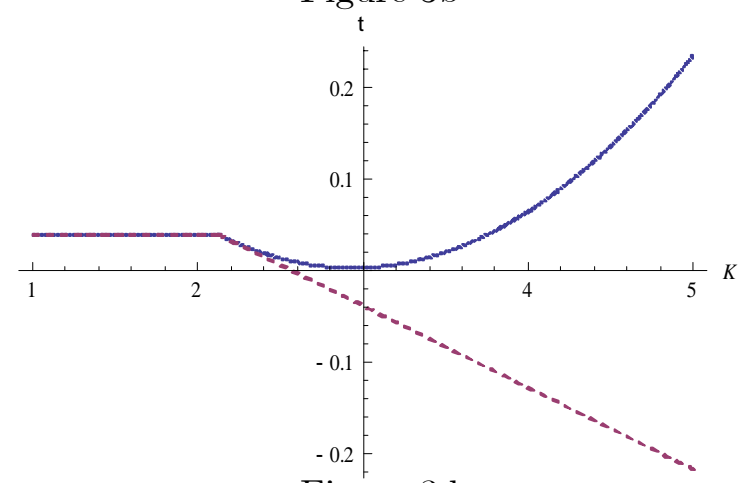

Figure 3d

Figures 3a to 3d plot $\tau^{[i, e]}$ (straight line) and $\tau^{[e, i]}$ (dashed line) as a function of project expected return $r_{\pi}$ (figure 2a), project return volatility $\sigma_{\pi}$ (figure $2 \mathrm{~b}$ ), entrepreneur's risk aversion $\gamma^{e}$ (figure 2c) and project's size relative to entrepreneur's wealth $K$ (figure $2 \mathrm{~d}$ ). Base case parameter values are in Table 4 . The $y$-axis is positioned at the base case value. The type of venture capital is independent. In all the plotted domains, endogenous $S^{*}$ is above 1 , hence a contract is feasible when $\tau^{[i, e]}>\tau^{[e, i]}$. 
Figure 4: Optimal choice of VC type.

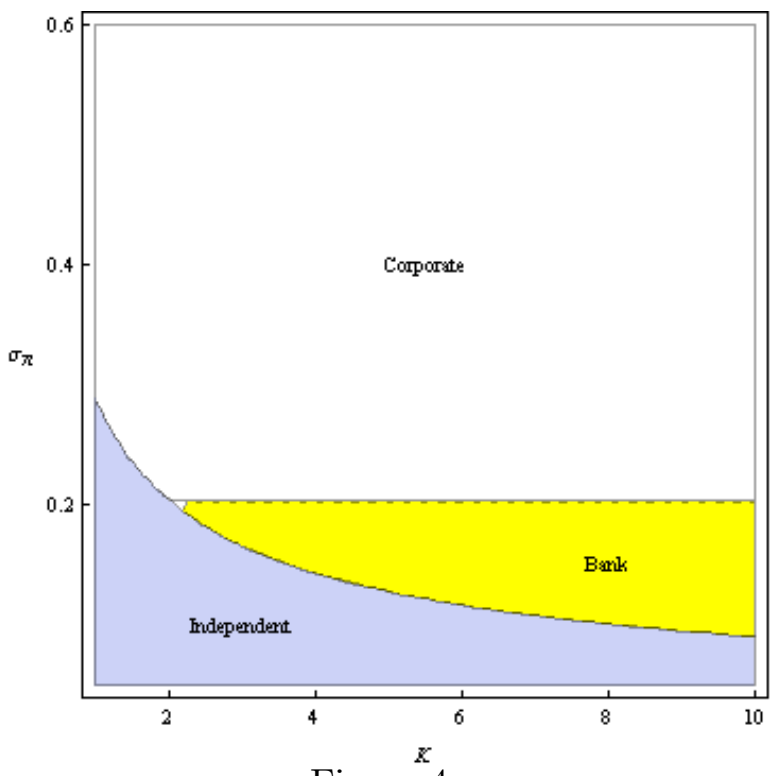

Figure $4 \mathrm{a}$

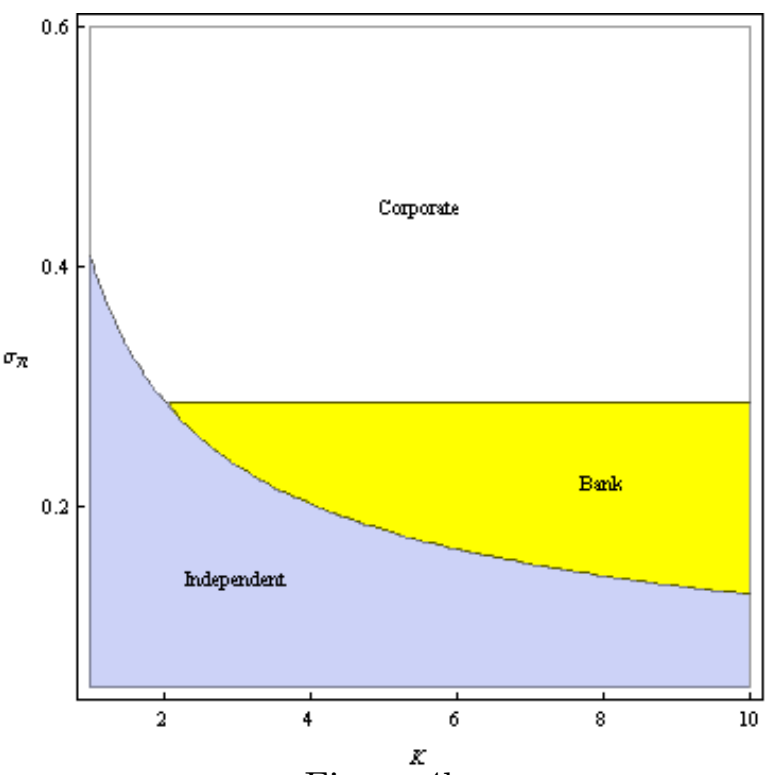

Figure $4 \mathrm{~b}$

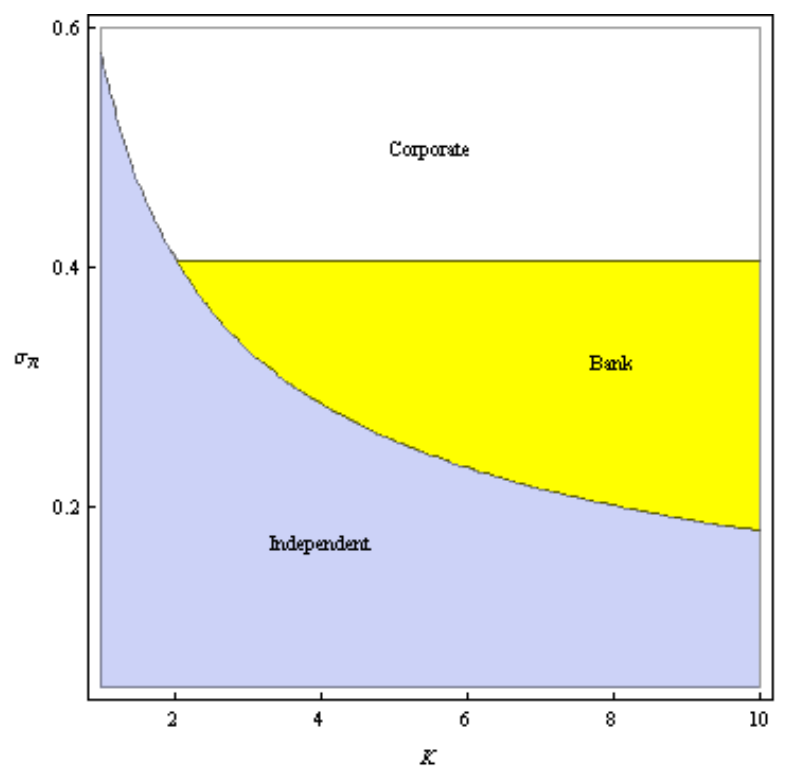

Figure $4 \mathrm{c}$

Figures $4 \mathrm{a}$ to $4 \mathrm{c}$ plot, as a function of project size $(K)$ and project risk $\left(\sigma_{\pi}\right)$, the type of venture capitalist that maximizes contract surplus with the entrepreneur. Base case parameter values are in Table 4 . In Figure 4a, entrepreneur's risk aversion is $\gamma^{e}=2$. In Figure 4b, it is $\gamma^{e}=1$. In Figure 4c, it is $\gamma^{e}=0.5$. 
Figure 5: Difference in contract surplus.

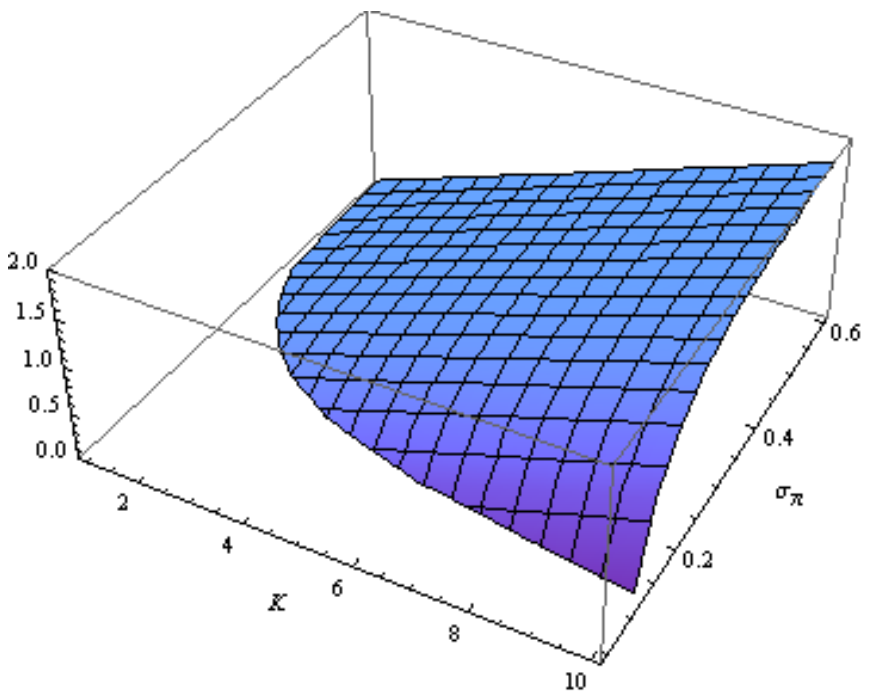

Figure 5a

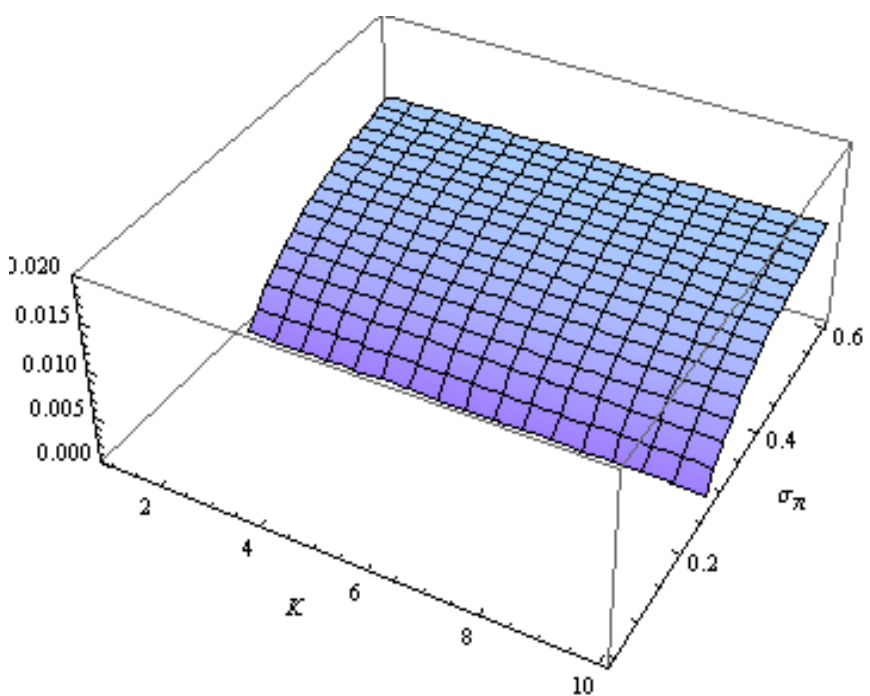

Figure $5 \mathrm{~b}$

Figures $5 \mathrm{a}$ and $5 \mathrm{~b}$ plot, as a function of project size $(K)$ and project risk $\left(\sigma_{\pi}\right)$, the difference in contract surplus between the corporate $\mathrm{VC}$ and the independent VC (Figure 5a), and between the corporate VC and the bank-sponsored VC (Figure 5b). Base case parameter values are in Table 4. 


\section{Figure 6: Endogenous dilution factor.}

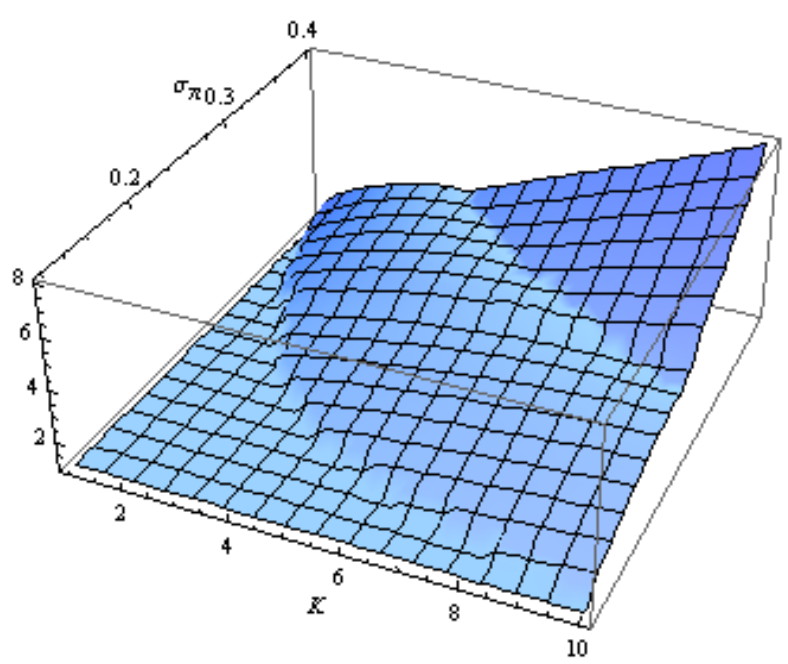

Figure 6 plots, as a function of project size $(K)$ and project risk $\left(\sigma_{\pi}\right)$, the dilution factor obtained from the optimal transfer rate. The VC type is endogenously determined. Base case parameter values are in Table 4 . 
Figure 7: Project risk and size characteristics per country.
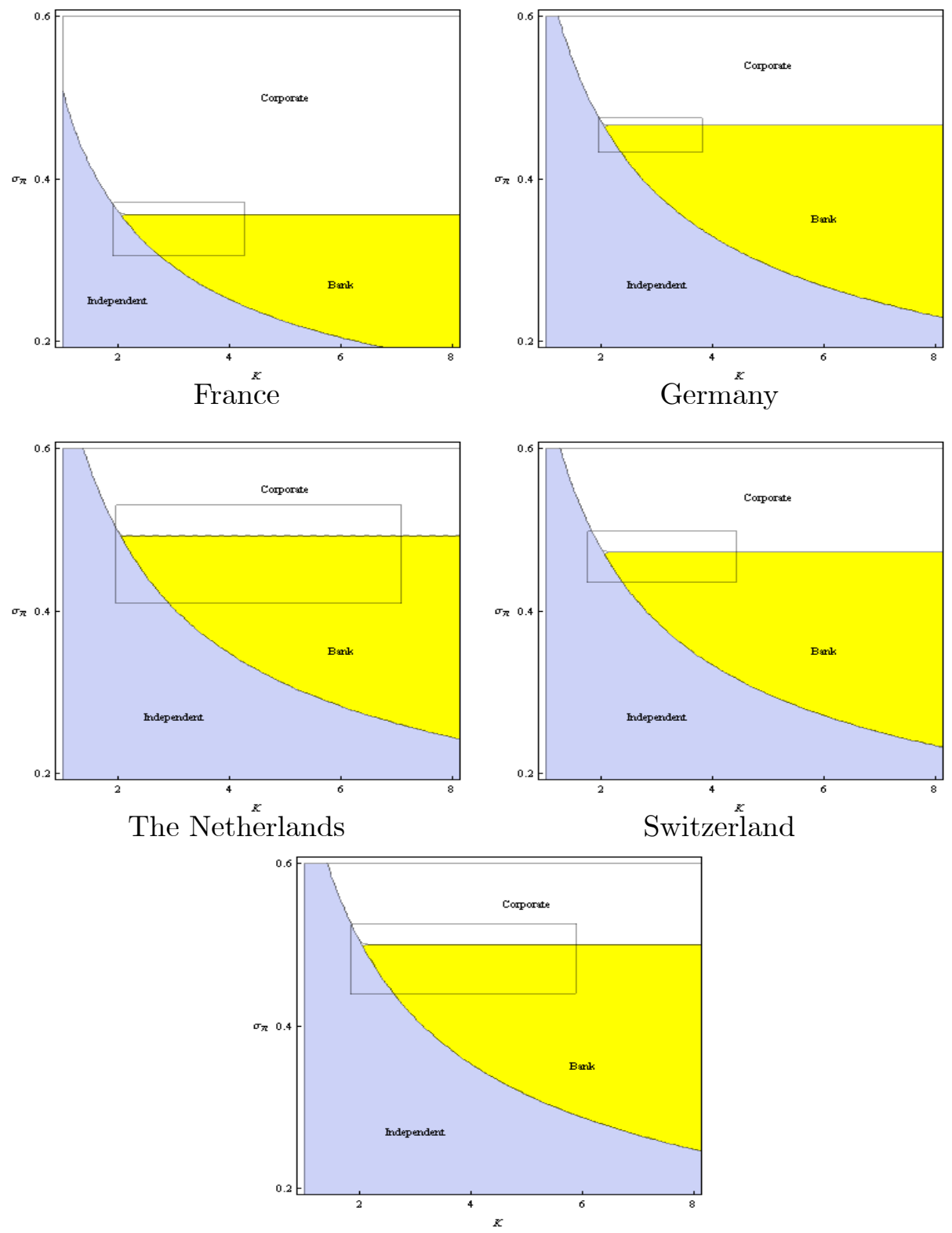

United Kingdom

Figure 7 reports the estimated range for project risk and project size that is consistent with observed median VC fund raising shares per investor type for the period 2002-2009. The range determination assumes a uniform distribution across project risk and project size. Numerical results are reported in Table 7. 
Figure 8: Investor type and stage financing.

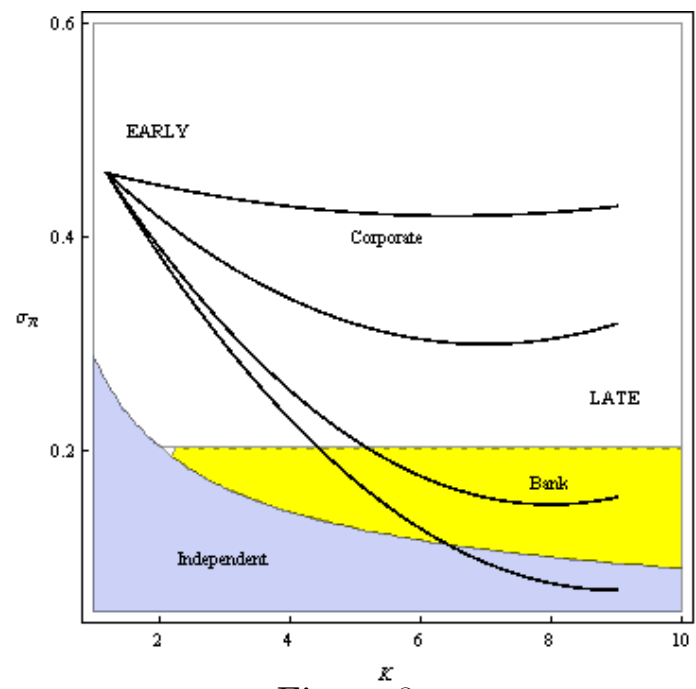

Figure $8 \mathrm{a}$

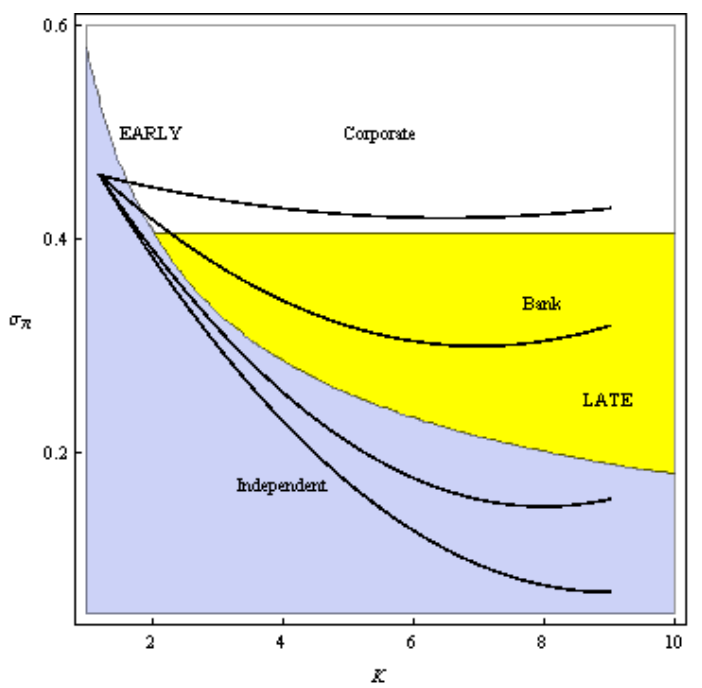

Figure 8b

Figures $8 \mathrm{a}$ and $8 \mathrm{~b}$ plot, as a function of project size $(K)$ and project risk $\left(\sigma_{\pi}\right)$, the type of venture capitalist that maximizes contract surplus with the entrepreneur. Superimposed are the typical paths followed by a venture through its different development stages. Base case parameter values are in Table 4. In Figure 8a, entrepreneur's risk aversion is $\gamma^{e}=0.5$. In Figure 8b, it is $\gamma^{e}=2$. 